\title{
Analysis of protein turnover by quantitative SNAP-based pulse-chase imaging
}

\author{
Dani L. Bodor, Mariluz Gómez Rodríguez, Nuno Moreno, and Lars E.T. Jansen* \\ Instituto Gulbenkian de Ciência \\ 2780-156, Oeiras \\ Portugal \\ *Correspondence: t: +351 21446 4519, f: +351 21440 7970, e: ljansen@igc.gulbenkian.pt \\ Running head: Fluoresent pulse-chase imaging and quantification
}

\begin{abstract}
Assessment of protein dynamics in living cells is crucial for understanding their biological properties and function. The SNAP-tag, a self labeling suicide enzyme presents a tool with unique features that can be adopted for determining protein dynamics in living cells. Here we present detailed protocols for the use of SNAP in fluorescent pulse-chase and quenchchase-pulse experiments. These time slicing methods provide powerful tools to assay and quantify the fate and turnover rate of proteins of different ages. We cover advantages and pitfalls of SNAP-tagging in fixed and live cell studies and evaluate the recently developed fast acting SNAPf variant. In addition, to facilitate the analysis of protein turnover datasets, we present an automated algorithm for spot recognition and quantification.
\end{abstract}

\section{Keywords}

SNAP; pulse-chase; quench-chase-pulse; centromeres; automated quantification; protein dynamics; protein turnover; quantitative fluorescence

\section{Introduction}

The ability to track specific populations of proteins over time in living cells is essential to gain insight into the dynamics of cellular processes. An array of methodologies exists that assess different aspects of protein dynamics in living cells. These include fluorescence recovery after photobleaching (FRAP), photoactivation, and recombination induced tag exchange (see Table 1 for a more extensive list).

Here we discuss SNAP-based pulse-chase imaging, a powerful method to track protein dynamics with distinct advantages over traditional methods to assess protein dynamics. SNAP is a suicide enzyme protein fusion tag that catalyzes its own covalent binding to the cell permeable molecule benzylguanine (BG), and (fluorescent) derivatives thereof (Figure 1; Damoiseaux et al., 2001; Keppler et al., 2003, 2004). Fusion of SNAP to a protein of interest allows this protein to be (fluorescently) labeled at will in living cells. Importantly, subsequent removal of the substrate results in the specific labeling of the initial pulse labeled pool. Changes in location and turnover of this pool can be determined and quantified. Moreover, serial labeling of SNAP-tagged proteins with different SNAP 
substrates distinguishes proteins synthesized at different times, such that "old" and "new" pools can be detected separately (Figure 3A and Jansen et al., 2007).

Principle advantages of using SNAP-tagging include 1) pools of protein synthesized at different times can be specifically visualized, which allows for determining the fate of preexisting versus newly synthesized pools of the same protein. 2) Because labeling occurs at a population basis, large numbers of cells can be analyzed in a single experiment. 3) Labeling and turnover occurs in the culture chamber rather than on the microscope stage. Therefore, cells are not continuously imaged, but sampled for imaging at any timepoint from hours to days post labeling. A more extensive comparison of SNAP with other pulse labeling techniques as well as its advantages and disadvantages can be found in Table 1 and below in the Background Information.

In this unit, we explain in detail how to perform a typical SNAP pulse labeling experiment in human cells. As an example, we will use HeLa cells that stably express a SNAP-tagged version of CENP-A, a centromere specific histone variant (Sullivan et al., 1994; Jansen et al., 2007). Using these CENP-A-SNAP cells, we have been able to show previously that the rate of centromeric CENP-A turnover corresponds to the rate of cell division, and thus that CENP-A turns over exclusively by dilution during DNA replication (Jansen et al., 2007). Using the same technology, we demonstrated that newly synthesized pools of CENP-A assemble specifically during G1-phase of the cell cycle (Jansen et al., 2007). The unique dynamics of CENP-A makes this an excellent illustration of the SNAP-labeling technique. However, this strategy is easily adaptable to other proteins (e.g. Figure 3 D) as well, and similar strategies have been used by us and other investigators, in a range of organisms and for different applications (Jansen et al., 2007; Erhardt et al., 2008; McMurray and Thorner, 2008; Maduzia et al., 2010; Bojkowska et al., 2011; Campos et al., 2011; Dunleavy et al., 2011; Silva et al., in press; also reviewed in O'Hare et al., 2007).

We will describe two typical types of SNAP-labeling strategies: Pulse-Chase (Basic Protocol 1) and Quench-Chase-Pulse (Basic Protocol 2), which allow for the analysis of old and new protein pools, respectively. We also describe potential ways to combine SNAP labeling with cell synchronization and siRNA mediated protein depletion (Basic Protocol 3). Cells can be either analyzed by live imaging (Basic Protocol 4) or fixed and combined with standard techniques such as immunofluorescence (Supporting Protocol 2). In addition, we present an unbiased, automated algorithm that is used for fluorescence measurements to quantify protein turnover (Basic Protocol 5) Lastly, we present an evaluation of SNAP pros, cons, pitfalls and ways to troubleshoot them as well as the recently developed variant of SNAP, SNAPf.

\section{Basic Protocol 1}

\section{Pulse-chase experiments}

This section will describe a general method that employs a pulse-chase strategy for analysis of a specific pool of protein in living cells. By using fluorescence pulse labeling, the fate and turnover rate of a given protein can be determined at a particular subcellular location. Specifically, SNAP-tagged protein that is present at the beginning of an experiment is fluorescently labeled (Pulse) followed by removal of excess dye. After a given amount of 
time (Chase), cells are analyzed e.g. for localization or quantity of remaining protein by (quantitative) fluorescence microscopy (Figure $2 \mathrm{~A}$ ). An example of a typical Pulse-Chase experiment of CENP-A-SNAP is shown in Figure $2 \mathrm{~B}$. In the approach described here, cells are fixed and analyzed at set time points following the initial pulse. As a consequence, protein dynamics can be determined at any time frame (hours, days) post labeling. However, the initial labeling and wash steps require approximately one hour, precluding the analysis of highly dynamic processes that occur at a timescale of seconds to minutes.

\author{
Materials \\ - Cells expressing SNAP-tagged fusion protein (see Supporting Protocol 1) \\ - Trypsin (cell culture grade, Gibco) \\ - Standard culture medium abbreviated to "CM" (see Reagents and Solutions). \\ - TMR-Star (see Reagents and Solutions). \\ - Sterile DMSO \\ - Sterile 1X PBS (cell culture grade, Gibco) \\ - 24-well plates \\ - Clean, sterile, poly-lysine coated coverslips (12 mm ø; Thickness 1.5) \\ - Vortex \\ - Table top centrifuge
}

\title{
Preparation of cells and SNAP-substrates
}

1) Prepare coverslips in separate wells of a 24-well plate to minimize the required incubation volumes. Trypsinize cells expressing SNAP-tagged fusion protein and seed onto the coverslips. Incubate at $37^{\circ} \mathrm{C}, 5 \% \mathrm{CO}_{2}$ (henceforth referred to as standard growth conditions). The cell density depends on a number of factors, mainly cell type and the number of days between seeding cells and fixation. Ideally, by the time of fixation, the cell density should be high enough to capture a significant amount of cells on each frame, but not too high such that cells are fully confluent. Generally 60-80\% confluency is ideal. For HeLa cells (duplication time $\sim 1$ day), we aim for having $\sim 5 \times 10^{5}$ cells at the time of fixation. E.g., $\sim 1 \times 10^{5}$ cells are seeded in the afternoon of day 1 , if fixation will take place in the morning of day 4.

2) Dilute TMR-Star stock to $2 \mu \mathrm{M}$ final concentration in CM. Vortex briefly to efficiently disperse the DMSO solvent into the aqueous medium. Dilute an equal volume of DMSO for mock labeling control. Prepare $>200 \mu \mathrm{l}$ per coverslip. Prepare TMR-Star working stock only as needed and use within the hour. Although labeling is not yet saturated at this concentration, we use $2 \mu \mathrm{M}$ to balance signal intensities and costs per experiment (see Critical Parameters and Troubleshooting for more details). DMSO addition is an important initial control to determine background fluorescence unrelated to SNAP-labeling, as well as to determine the effect of DMSO on the cells. Once these factors have been established and an effect on cell viability, cell cycle progression, etc. are excluded for a given cell line, this control can be omitted from subsequent experiments.

3) Spin diluted TMR-Star for 5 minutes at maximum speed $(\sim 16.000 \mathrm{~g})$ in a microcentrifuge to get rid of possible insoluble fluorescent debris. Recover as much of the supernatant as possible without disturbing the pellet (may not be visible). Omitting this step will result in occasional but very bright fluorescent aggregates that interfere with imaging and quantification of fluorescent signals.

\section{Pulse labeling and washes}


4) Aspirate CM from cells and add $200 \mu \mathrm{l}$ of CM+TMR-Star or CM+DMSO. Incubate for 15 minutes at standard growth conditions. TMR-Star treatment of cells will likely result in non-specific fluorescence (see Critical Parameters and Troubleshooting). It is therefore important to conduct pilot experiments in which the parent cells without expression of SNAP is labeled to discriminate SNAP dependent fluorescence from unspecific TMR-Star fluorescence.

5) Wash cells twice with $1 \mathrm{ml}$ sterile PBS (pre-heated to $37^{\circ} \mathrm{C}$ ) to wash away free substrate. Re-incubate cells in CM under standard growth conditions for an additional 30 minutes. In our experience, in experiments where the cells have undergone multiple consecutive treatments prior to labeling (e.g. synchronization, RNAi, drug treatments), it is preferable to perform the washes with CM rather than PBS in this and the following steps. This enhances cell survival.

6) Wash cells twice with $1 \mathrm{ml}$ sterile PBS (pre-heated to $37^{\circ} \mathrm{C}$ ). This second wash is important to remove any substrate that was retained in the cells after the initial wash. In our experience, omitting this step leads to a significant increase in background fluorescence. We calculate the chase period from the completion of this wash step, as this indicates the last time point during which SNAP-tagged proteins can be fluorescently labeled.

\section{Chase and post processing}

7) There are 3 general options to proceed. Details are presented in subsequent sections:

a. Pulse-Fix: Fix cells immediately after the second wash and either image directly or process for immunofluorescence (Supporting Protocol 2). This allows testing for SNAP-expression levels and/or serves as a control for subsequent Pulse-Chase experiments.

b. Pulse-Chase: Re-add $1 \mathrm{ml}$ of $\mathrm{CM}$ and incubate cells in standard growth conditions for a given amount of time (chase period), after which cells are fixed and treated for immunofluorescence (Supporting Protocol 2).

c. Pulse-Image: Mount cells for live imaging (Basic Protocol 4).

\section{Basic Protocol 2}

\section{Quench-chase-pulse experiments}

In this section we describe a general method that allows for the analysis of a 'new' pool of protein. Specifically, the pool of SNAP-tagged protein that is present at the onset of an experiment is labeled by a non-fluorescent SNAP-substrate (Quench). Subsequently, after a given amount of time (Chase), cells are labeled with a second, fluorescent substrate (Pulse). In this way only the pool of protein synthesized during the chase period is fluorescently labeled and hence will be visible by microscopy (Figure 3A), while the initial quenched pool remains undetected (Figure $3 \mathrm{~B}$ ). This approach allows for e.g. quantitative and temporal analysis of protein translocation and/or assembly into subcellular domains. Examples of typical Quench-Chase-Pulse experiments are shown in Figures 3C and D.

\section{Materials}

- All materials used in Basic Protocol 1. In addition:

- BTP (see Reagents and Solutions) 


\section{Preparation of cells and SNAP-substrates}

1) Prepare coverslips and cells as in step 1 of Basic Protocol 1.

2) Dilute BTP to $2 \mu \mathrm{M}$ final concentration in CM. Vortex briefly to efficiently disperse the DMSO solvent into the aqueous medium. Prepare $>200 \mu \mathrm{l}$ per coverslip. Prepare BTP working stock only as needed and use within the hour. We have successfully used BTP at concentrations as low as $0.2 \mu \mathrm{M}$, resulting in fully quenched SNAP-labeling. However, because full quenching is essential for accurate interpretation of the results, we prefer using BTP at an excess of $2 \mu \mathrm{M}$ (see step 6 for determination of quench efficiency).

\section{Quench labeling and washes}

Quench labeling is performed much in the same way as the pulse labeling described in Basic Protocol 1. The main difference is the time of initial incubation with BTP: 30 minutes, as compared to 15 minutes for TMR-Star (compare step 3 of this protocol with step 4 of Basic Protocol 1).

3) Aspirate CM from cells and add $200 \mu \mathrm{l}$ of $\mathrm{CM}+\mathrm{BTP}$ or $\mathrm{CM}+\mathrm{DMSO}$. Incubate for 30 minutes at standard growth conditions.

4) Wash cells twice with $1 \mathrm{ml}$ sterile PBS (pre-heated to $37^{\circ} \mathrm{C}$ ) to wash away free substrate. Re-incubate cells in CM and standard growth conditions for an additional 30 minutes. In our experience, in experiments where the cells have undergone multiple consecutive treatments prior to labeling (e.g. synchronization, RNAi, drug treatments), it is preferable to perform the washes with CM rather than PBS in this and the following steps. This enhances cell survival.

5) Wash cells twice with $1 \mathrm{ml}$ sterile PBS (pre-heated to $37^{\circ} \mathrm{C}$ ). The second wash is important to remove all traces of free BTP. Omission of this wash will lead to continued quenching of a proportion of newly synthesized protein during the chase resulting in smaller pool size of subsequently labeled nascent protein. We calculate the chase period from the completion of this wash step, as this indicates the last time point during which SNAP-tagged proteins can be labeled by the non-fluorescent substrate.

\section{Quench-Pulse control}

6) Label at least one coverslip with TMR-Star directly following the quench step (no chase) as described in steps 2 through 7 of Basic Protocol 1. This is a very important control experiment, as it indicates whether or not the preexisting SNAP-tagged protein is fully quenched by the available BTP (Figure $3 \mathrm{~B}$ ). If this is not the case, results are very difficult, if not impossible, to interpret correctly. If BTP labeling is not complete, it may be necessary to increase the concentration of BTP and/or the incubation time. Once conditions that lead to a complete quenching of SNAP-tagged protein has been determined for a particular cell type Chase and application, this control can be omitted in subsequent experiments.

7) Re-incubate cells in CM under standard growth conditions for the appropriate time. Chase times will dependent, amongst other things, on the expression levels of the protein of interest and cell type used. Typically in human cell culture a chase of several hours is required to create a pool size large enough for subsequent visualization by pulse labeling (e.g. for the case of CENP-A-SNAP, we found the minimum chase time required to detect nascent protein is 3 hours).

\section{Pulse labeling and washes}

8) For fluorescent pulse labeling and downstream applications, follow steps 2 through 7 from Basic Protocol 1. 


\section{Basic Protocol 3}

\section{Integrating cell synchronization and RNAi in SNAP-based quench-chase-pulse labeling experiments.}

In this section we will describe how to combine the SNAP-labeling procedure with cell synchronization and/or siRNA mediated protein depletions, specifically in HeLa cells. We will give a full overview of multiple synchronization and depletion steps integrated into a single quench-chase-pulse experiment (Figure 4A). This allows for the determination of the fate of a newly synthesized pool of protein during the cell cycle and in response to protein depletions. It should be noted that depending on the specific experiment, in many cases not all steps will be required. An example of a typical synchronized Quench-Chase-Pulse experiment is shown in Figure 4B.

\section{Materials}

- All materials used in Basic Protocol 2. In addition:

- Thymidine, stock of $50 \mathrm{mM}$ in water.

- Deoxycytidine, stock of $24 \mathrm{mM}$ in water.

-Transfection reagents for siRNAs (e.g. Oligofectamine (Invitrogen), and associated products).

- siRNAs

- Nocodazole stock $5 \mathrm{mg} / \mathrm{ml}$

- MG132 stock of $10 \mathrm{mM}$

\section{Preparation of cells and synchronization and RNAi}

1) Prepare cells on coverslips as described in step 1 of Basic Protocol 1.

2) Perform siRNA transfection for analysis of RNAi mediated protein depletion at 4872 hours post transfection. This step is performed as described in the product description protocol for Oligofectamine (Invitrogen). Wait at least 4-5 hours before proceeding to step 3. Protein depletion can only be performed at this point in the protocol (of a synchronized experiment) if the depleted proteins are not involved in cell cycle progression. For proteins that are likely to interfere with $S$ - or M-phase transition, siRNA transfection is best performed at a later stage in the protocol (see steps 5 and 9).

3) Add thymidine to the $\mathrm{CM}$ at a final concentration of $2 \mathrm{mM}$ and incubate cells at standard growth conditions for 17 hours. Cells that are in S-phase when thymidine is added will arrest immediately, while other cells progress until they enter S-phase and arrest there. Thus, after 17 hours, all cells will be arrested in S-phase albeit at different stages of Sphase completion. Spike in thymidine rather than replacing the CM with CM+thymidine (if RNAi was performed during step 2), as this would wash out siRNAs from the medium and reduce the efficiency of protein depletion. If siRNAs are transfected with oligofectamine in serum free medium in step 2 then serum can be re-added (along with thymidine) at this point to a final concentration of $10 \%$.

4) Release cells from thymidine arrest by performing two washes with CM, followed by addition of $\mathrm{CM}+$ deoxycytidine $(24 \mu \mathrm{M}$ final concentration $)$. Incubate cells at standard growth conditions for 9 hours. 


\section{Quench labeling and washes}

5) At 5 hours after release from the first thymidine arrest, siRNA transfection can be performed for analysis of RNAi mediated protein depletion at 24-48 hours post transfection. This step is performed as described in the product description protocol for Oligofectamine (Invitrogen). Protein depletion can be performed at this point in the protocol for proteins that are (likely to be) required for mitotic progression, because significant levels of protein depletion are generally only observed at least 4-5 hours after siRNA transfection. At this point ( 10 hours after release from the first thymidine arrest), most cells will have passed through mitosis already. For proteins that are not involved in cell cycle progression, siRNA transfection can be performed at an earlier point (see step 2), while proteins that are involved in S-phase progression are best depleted at a later point (see step 9).

6) 9 hours after the release described in step 4, add thymidine to the CM to a final concentration of $2 \mathrm{mM}$. Incubate cells at standard growth conditions for 15.5 hours. At this time all cells will have finished DNA replication, while none have started the next $S$ phase, regardless at which point in S-phase they were arrested initially. Spike in thymidine rather than replacing the CM with CM+thymidine (if RNAi was performed during step 5), as this would wash out siRNAs from the medium and reduce the efficiency of protein depletion. If siRNAs are transfected with oligofectamine in serum free medium in step 5 then serum can be re-added (along with thymidine) at this point to a final concentration of $10 \%$.

7) 15.5 hours after thymidine addition in step 6, perform quench-labeling (and $1^{\text {st }}$ washout thereof) essentially as described in steps 3-6 of Basic Protocol 2, except that $2 \mathrm{mM}$ thymidine is added to the $\mathrm{CM}+\mathrm{BTP}$ and $\mathrm{CM}$ in order to maintain cells in the $S$-phase arrest until after the labeling is complete.

8) 30 minutes after step 7, release cells from second thymidine arrest and perform second BTP washout by performing two washes with $\mathrm{CM}$, followed by addition of $\mathrm{CM}+$ deoxycytidine $(24 \mu \mathrm{M}$ final concentration). This step combines the second wash of the BTP-labeling and release from second thymidine arrest. Cells will now (16 hours after initiation of second thymidine arrest) all be synchronously released from early S-phase and will progress through the cell cycle largely synchronous for approximately one full cell cycle. Cells will enter mitosis at 9-11 hours after release from the second thymidine arrest.

\section{Chase}

9) $\sim 3$ hours after release from the second thymidine arrest (step 8), siRNA transfection can be performed for analysis of RNAi mediated protein depletion at early timepoints post transfection. This step is performed as described in the product description protocol for Oligofectamine (Invitrogen). Protein depletion can be performed at this point in the protocol for proteins that are (likely to be) required for S-phase progression, because significant levels of protein depletion are generally only observed at least 4-5 hours after siRNA transfection. At this point ( 8 hours after release from the second thymidine arrest), most cells will have passed through $S$-phase already. Since maximum protein depletion is generally observed 24-48 hours post-transfection, for proteins that are not involved in $S$ phase progression, siRNA transfection are best performed at an earlier point (see steps 2 and 5).

\section{Pulse labeling and washes}

10)TMR-Star pulse labeling and downstream applications are performed as described in Basic Protocol 1, steps 4-7 at different time points following BTP-quench and thymidine release depending on the application. If siRNAs are transfected with oligofectamine in serum free medium in step 9 then serum can be re-added after $2^{\text {nd }}$ washout of TMR-Star. 
11)Optional: To gain higher synchrony in and around mitosis, cells can be arrested in mitosis by addition of the microtubule depolymerizing drug nocodazole to 250 $\mathrm{ng} / \mathrm{ml}$ final concentration will result in a prometaphase arrest), or addition of nocodazole and washout of this drug into the proteasome inhibitor MG132 $(24 \mu \mathrm{M}$ final; metaphase arrest). Nocodazole can be added at any time to allow accumulation of cells in mitosis (optimal concentration will depend on cell type). MG132 will arrest cells in interphase unless added in late G2-phase in which case cells will continue to cycle until metaphase. Metaphase synchronization of cells by MG132 is therefore best combined with a (double thymidine arrest, release and) nocodazole arrest and release. Arrest from these drugs is reversible, allowing the analysis of cells that are synchronously released from mitosis.

12)Optional: 9 hours after release from the second thymidine arrest, thymidine (final concentration of $2 \mathrm{mM}$ ) can be re-added to collect cells synchronously at the next G1/S-phase transition, 15 hours later.

\section{Alternate Protocol \\ Integrating cell synchronization and RNAi in SNAP-based pulse-chase labeling experiments.}

In this alternate protocol we describe a modified version of Basic Protocol 3, where a PulseChase strategy is employed rather than a Quench-Chase-Pulse. This allows for tracking of a pre-existing pool of SNAP (as opposed to a newly synthesized pool) in relation to the cell cycle and in response to protein depletions. This protocol is highly similar to the Basic Protocol above and therefore we will only describe the key steps that are different between the two protocols.

This alternate protocol can also be performed in parallel with Basic Protocol 3, e.g. to distinguish a differential effect on separate pools of the same protein (an example is given in Figure 4C).

\section{Materials}

All reagents used in Basic Protocol 3, except for BTP

\section{Preparation of cells and synchronization and RNAi}

1) Cells are prepared, and treated with siRNAs and synchronized with thymidine as described in Basic Protocol 3 steps 1-6.

\section{Pulse labeling and washes}

2) $15 \mathrm{~h}$ and 15 minutes after thymidine addition in step 6 of Basic Protocol 3, perform TMR-Star pulse labeling (and $1^{\text {st }}$ washout thereof), essentially as described in steps 4-6 of Basic Protocol 1, except that $2 \mathrm{mM}$ thymidine is added to the CM+TMR-Star and $\mathrm{CM}$ in order to maintain cells in the $\mathrm{S}$-phase arrest until after the labeling is complete.

3) 30 minutes after step 2, release cells from second thymidine arrest and perform second TMR-Star washout by performing two washes with CM, followed by addition of CM+deoxycytidine ( $24 \mu \mathrm{M}$ final concentration). This step combines the second wash of the TMR-Star-labeling and release from second thymidine arrest. 
4) Proceed to downstream applications as described in step 7 of Basic Protocol 1.

\section{Basic Protocol 4}

\section{Live imaging of pulse labeled cells.}

This section will describe the basic procedure and considerations of imaging SNAP substrate signals in living cells. Live cell imaging of SNAP labeled proteins differs from conventional imaging of autofluorescent proteins (e.g. GFP) in that SNAP substrates generate considerable background staining, particularly in membrane compartments. This requires specific signals to be of sufficient strength to maintain an adequate signal-to-noise ratio. Despite this constraint, live cell imaging of temporally labeled SNAP-tagged proteins is a powerful approach to determine the fate of protein pools of different ages (Figure 5).

\section{Materials}

Specific reagents and materials for different live cell imaging methods are specified in subsections below.

Common materials:

- Materials and reagents for SNAP pulse labeling as described in Basic Protocol 2. In addition:

- Live imaging medium, referred to as "LM" (see Reagents and Solutions).

- Microscopy facilities suitable for live cell imaging (see below for some general considerations)

Live-cell imaging setups for SNAP-tagged cells are similar to those of normal live cell setups. We use typically 2 different methods.

Method 1: double side sticky tape chamber. This method is adapted from (WatermanStorer and Salmon, 1997).

\section{Specific Materials}

- VALAP (see Reagents and Solutions)

- Oxyrase (Oxyrase Inc.), stock of $30 \mathrm{U} / \mathrm{ml}$

- 6-well plates

- 22x22 mm square coverslips

- Permanent double-sided tape (Scotch)

- Standard glass slides

\section{Preparation of cells and pulse labeling}

1) Grow cells expressing SNAP-tag fusion proteins in 6-well plates onto $22 \times 22 \mathrm{~mm}$ square glass coverslips in $2 \mathrm{ml}$ of culture medium to $60-80 \%$ confluency.

2) Perform quench and pulse labeling steps as in Basic Protocols 1 or 2, except that labeling volumes of $600 \mu \mathrm{l}$ are used in 6-well plates.

\section{Mounting of live cell chambers}


3) Glue 3 layers of double-sided tape, cut to $\sim 3 \mathrm{~mm}$ wide, along the two long edges of the glass slide such that when a coverslip is placed on top, it is sealed on two sides (along the longitudinal end of the glass slide).

4) Mount coverslips, cells facing down, onto the glass slide prepared in step 3.

5) Slowly, flow in LM under the coverslip, until the chamber is filled by capillary action $(<1 \mathrm{ml})$. Perform this step as quickly as possible after step 4 to avoid cells drying out. Phenol red is omitted from the LM to avoid background fluorescence. The use of $\mathrm{CO}_{2}$ independent medium (e.g. buffered by HEPES) is required to maintain $\mathrm{pH}$ in this chamber type as it is sealed from outside air contact. Optionally, $0.5 \mathrm{U} / \mathrm{ml}$ Oxyrase is included in the medium. Oxyrase is an oxygen-scavenging enzyme that helps reduce photobleaching and phototoxicity due to reactive oxygen species.

6) Seal the chamber on all sides with VALAP and image live cells on the microscope.

\section{Method 2: 8-well coverglass slides.}

\section{Specific Materials}

- 8-well Chambered Coverglass (Lab-Tek)

- Mineral oil

\section{Preparation of cells and pulse labeling}

1) Grow cells expressing SNAP-tag fusion proteins directly in an 8-well chambered coverglass slides to $60-80 \%$ confluency.

2) Perform Quench and Pulse labeling steps as in Basic Protocols 1 or 2, except that labeling volumes of $100 \mu \mathrm{l}$ are used in 8-well chambered coverglass slides.

\section{Mounting of live cell slides}

3) Following labeling and washes, replace medium with LM to a final volume of $300 \mu \mathrm{l}$. Seal wells with $100 \mu \mathrm{l}$ mineral oil. Due to small sample volumes it is critical to prevent evaporation of medium during the time lapse. Sealing of the medium-air interface with mineral oil is an effective method to achieve this. The use of mineral oil is compatible with the use of DIC optics during live cell imaging.

\section{General considerations regarding the microscope setup.}

A detailed description of microscope parameters is outside the scope of this unit. Typically, for live cell imaging of mammalian cells, a heated chamber is required to maintain both the cells and the microscope stage at the appropriate temperature. SNAP-dyes can be imaged in principle with any microscope setup as long as appropriate laser lines or filters are used. A variety of fluorescent SNAP-substrates is available from New England Biolabs and others can be found in the existing literature (e.g. Keppler et al., 2004, 2006). See also Critical Parameters and Troubleshooting below.

Fluorescent SNAP substrates are based on organic dyes (e.g. TMR). Bleaching is therefore not as big a concern as with autofluorescent proteins such as GFP or RFP. However, due to non-specific labeling (of membranes), background signals are relatively high as compared to autofluorescent proteins. Exposure times, laser strength, neutral density filter settings, and choice of temporal resolution largely depend on signal strength and considerations of cellular phototoxicity. 


\section{Basic Protocol 5}

\section{Automated quantification of SNAP-tagged protein turnover at centromeres.}

In this section we will present a method to perform unbiased fluorescence quantification of diffraction limited spots. We present here a case for centromeres, but this approach applies to any point source signals in living or fixed cells. To this end, we developed an automated algorithm which we name CRaQ (Centromere Recognition and Quantification). This ImageJ based macro detects spots in one channel and subsequently measures the fluorescence intensities in another. This allows for accurate detection and quantification of thousands of spots in a fast, unbiased, and effortless way.

In brief, centromeres are recognized and the centroid position is determined. Next, fluorescent intensities are measured for each centromere by placing a small box around the centroid position of the centromere. The peak intensity value within the box is then corrected for local background by subtraction of the minimum pixel value. This process results in an accurate measurement of centromere specific signals.

Because this protocol is performed in an automated fashion, in this section we will first describe the steps that the researcher must take (preparation of the data, CRaQ initiation and parameter settings, etc). Next, we will give an overview of the actual steps that the algorithm goes through for each image (Figure 6A-E). This provides users with a good idea of how automated recognition and quantification is performed.

We have evaluated the accuracy of CRaQ by re-analyzing previously published quantifications that were performed by manually selecting spots (in a reference channel) by eye (Jansen et al., 2007). The results that are obtained by CRaQ are practically identical to the previously published results (Figure 6F). In addition, we evaluated the robustness of $\mathrm{CRaQ}$ by analyzing replicates samples. Because $\mathrm{CRaQ}$ works in a deterministic fashion, reanalyzing an identical dataset without changing parameters will lead to an identical result. We show that quantification of replicate samples by CRaQ leads to results with a standard error of the mean (SEM) of $\sim 5 \%$, which is likely attributable to biological and/or experimental variation (Figure 6G).

\section{Materials}

- A standard computer

- ImageJ software, including the "Grouped_ZProjector" plugin (both freely available from NIH, http://rsbweb.nih.gov/ij/index.html)

- CRaQ plugin for ImageJ (Appendix 2 or freely available from http://uic.igc.gulbenkian.pt/micro-macros.htm).

- Digital images of SNAP-labeled cells, as described in Basic Protocol 1 or 2 after fixation and antibody staining as described in Supporting Protocol 2.

\section{Input data preparation (before running CRaQ)}

1) Input files should consist of all of the channels of a single frame in one file. CRaQ can use either stacks or projected images as an input. The order of images in a file should be such that the entire image sequence of one channel is followed by the image sequence of the second channel, etc. This as opposed to having all channels for 
one frame followed by the all the channels for the next frame. Additional channels that are not used during the quantification process can be stored in the same files and will be ignored by $C R a Q$.

2) Note the order in which the data, reference and DAPI channels are stored in the input files. In principle, only a data channel (the channel that will be quantified) is essential for CRaQ to run. See Critical Parameters and Troubleshooting for reasons and tips for using an independent reference channel.

3) Ideally, the order in which the images should be taken is 1) data, 2) reference, 3) DAPI, and 4) any additional channels. In this way, potential bleaching of the data signal during reference or DAPI channel acquisition will occur only after the data have been collected.

4) Create a "base folder" with separate subfolders that contain all the images for each condition (e.g. RNAi, replicates, cell types, cell cycle stages, etc). Any images that are located directly in the base folder will not be detected by CRaQ. If all images are to be quantified separately, they can be put into a single subfolder, as the output data file indicates which data points are derived from which image. Only files with extension ".dv" (produced by SoftWorx, Applied Precision) or ".tif" will be recognized by the macro. Thus additional files (log files, etc.) can remain in the base folder without interfering with the macro. When rerunning CRaQ on a previously analyzed data set (e.g. using different settings), make sure to copy the previous data output prior to rerunning, as all files will be overwritten.

\section{Installing and Running CraQ:}

5) Copy the CRaQ plugin into your “.../ImageJ/plugins/Analyze” folder and restart ImageJ. Run the algorithm by selecting it from the Plugins>Analyze menu inside ImageJ.

6) In the window that appears you can set the order in which the Data, Reference, and DAPI channels are stored in the input files, as well as the total number of channels. In addition, you can choose to change the standard parameter settings of CRaQ.

\section{Setting the Parameters:}

The default parameters are those that we have found to work best for most purposes. However, depending on particular experiments, this will not always be the case. What follows is an explanation of each parameter and how and why to change them.

a. Square size.

The size of the box placed around each centromere. Square size 7 means a box of $7 x 7$ pixels. This will generally not change the results much, as only the maximum and minimum pixel values in each box are used. However, make sure that the box is big enough to contain some background pixels, but not too large, as this will make the background signal "less local" and will decrease the number of spots identified due to exclusion of overlapping boxes.

b. Minimum Circularity.

This measure helps to exclude clustered centromeres. Circularity is a measure of how much the recognized spots resemble a circle, where 1 is a perfect circle and 0 a straight line (the most imperfect circle). Since centromeres appear as diffraction limited spots, they should theoretically be perfectly circular and this measure can be set very close to 1 (most single centromeres actually have a circularity of 1). Because brighter centromeres tend to be less circular, decreasing circularity will allow you to pick up more bright centromeres, but will also increase the chance of picking up doublets, clusters or non-centromeric regions.

c. Max Feret's Diameter 
This measure is also made to exclude doublets/clusters and is required because occasionally clusters have a very high circularity. The feret's diameter is the longest diameter of a spot. Together, stringent circularity and feret parameters are able to exclude most doublets. Increasing the maximum feret's diameter has a similar effect to decreasing minimum circularity and vice versa.

d. Min/Max Centromere Size

The minimum and maximum size a centromere can have (in total number of pixels). Basically having a larger maximum size can include both brighter centromeres and more doublets. Again, a lower max centromere size will exclude the last few doublets, but may also exclude some of the brightest (in the reference channel) single centromeres. Increasing the minimum will discard more false positive spots, but also more truly positive (dim) spots.

e. Threshold offset

This parameter sets the sensitivity of recognition of spots in the thresholded image. Increasing the offset makes the threshold more sensitive to lower signals. This will both increase the number of dim spots (true \& false positives), and decrease the number of bright centromeres (false negatives), as these will now appear bigger and potentially less circular.

f. Chromatic aberration correction

If there is a constant chromatic aberration between reference and data channels, this can be corrected by CRaQ. If the reference channel has spots shifted towards the top/right, then input positive numbers. If the reference channel has spots more to the bottom/left, input negative numbers.

\section{Data output:}

All output files will be produced in an output folder inside the base folder. These are the different output files that will be produced by CRaQ:

a. A single file entitled: "logfile.txt".

This file contains the base directory and parameter settings used. Keep this file or copy info for further reference, replicate experiments or comparison between experiments and parameter settings.

b. One "*.txt" file for each condition (i.e. subfolder of the base folder).

These files contain the actual measurements made by CRaQ with a reference to the corresponding image and centromere spot. These can be directly copied to analysis software such as Excel (Microsoft) or Prism (Graphpad) for further data processing and analysis.

c. One “*.zip" file for each image.

This contains all the recognized spots for that image as ROI lists for ImageJ. To view spots, open the image and the corresponding *.zip file in ImageJ. A "ROI Manager" window will appear, and you can either see all spots by selecting "Show all" or select and display any individual spot.

$\mathrm{d}$. If stacks where used as input images, a projection of each image is saved. All channels of an image will be saved together in a single *.tif file.

\section{How it works:}

1) Convert DAPI to mask (Figure 6A). This mask will exclude any spots that are recognized but do not overlap with DNA.

2) Signal enhancing on reference (Figure $6 \mathrm{~B}$ ). This allows for more accurate spot recognition.

3) Overlay the mask and the reference (Figure 6C). This excludes any non-DAPI signals.

4) Spots that are significantly above background and fall within the restrictions given by the parameter settings are detected and exported as ROI (region of interest) lists (Figure $6 \mathrm{D})$. Note that generally $<50 \%$ of all centromeres are found. However, the recognition of centromeres does not seem to depend on the brightness of centromeres in the reference channel, much the less in the data channel. Exclusion of centromeres occurs mostly 
based on too close proximity to other centromeres. Even though many centromeres are excluded, these measurements will always be orders of magnitude faster and less biased than doing the same by hand.

5) Measure the centromere spots in the data channel (Figure 6E). A box of a set size is placed around the center of mass of a ROI. In these boxes, the maximum and minimum values of the Data channel will be measured. The minimum is subtracted from the maximum and that is represented in output. In addition, these boxes are also saved as output. Note that no transformations or background subtractions, etc are made to the Data file before measuring. This means that you are actually measuring raw data. Alterations are only made (but not saved) in the other channels, and are used to efficiently localize centromeres. To exclude overlapping boxes, thus measuring the same spot twice, each box is made black after being measured (value $=0$ ). The macro is programmed to exclude any box containing pixels of value 0 . These black boxes are not saved to the data file, so that raw data is preserved. If there is a chromatic aberration, this can be set in the parameters (see above) and boxes are shifted accordingly before measuring. The saved output boxes are the ones that correspond to the reference channel.

\section{Supporting Protocol 1}

\section{Expression of SNAP-fusion proteins.}

We use SNAP source vectors that include a triple HA tag for efficient detection of SNAPtagged proteins by immunoblotting or immunofluorescence. Maps of SNAP-3XHA, 3XHASNAP and 3XHA-SNAPf vectors are shown in Appendix 1. Fusion proteins are subsequently subcloned in transient expression vectors or in retroviral constructs (pBABE, see below) for stable expression.

For piloting SNAP fusion performance in living cells, we use standard transient transfection methods for obtaining SNAP protein expression. We transfect cells using liposome based methods [e.g. Lipofectamine (Invitrogen) or Fugene (Roche) according to manufacturer's instructions] and assay protein expression and SNAP activity 48 hours after transfection.

For comprehensive experiments, we typically use monoclonal cell lines stably expressing SNAP fusions obtained by retroviral mediated transduction and selection. We use recombinant Moloney murine leukemia (Mo MuLV) retroviral particles for the delivery of SNAP-tagged transgenes into host cell lines (e.g. HeLa or hTERT-RPE). This system is derived from a set of pBABE retroviral vectors (Morgenstern and Land, 1990). Virus particles are assembled in HEK293-GP cells that express the essential Mo MuLV gag and pol genes along with transient delivery of the vesicular stomatitis virus G protein (VSV-G) that results in a pantropic virus with a broad host cell range (Burns et al., 1993; Yee et al., 1994).

\section{Materials}

- HEK 293-GP cells (Burns et al., 1993).

- Trypsin (Cell culture grade, Gibco)

- Standard culture medium abbreviated to "CM" (see Reagents and Solutions).

- Lipofectamine LTX (Invitrogen) and associated products

- Sterile PBS (Cell culture grade)

- Polybrene (hexadimethrine bromide , Sigma) $8 \mathrm{mg} / \mathrm{ml}$ 
- Selection drugs (e.g. Blasticidin S, puromycin, or hygromycin)

- Bovine serum albumin (BSA)

- $10 \mathrm{~cm}$ standard cell culture dishes

- $10 \mathrm{ml}$ syringes

$-0.45 \mu \mathrm{m}$ filters

- 6-well plates

- 96-well plates

- Single cell sorting equipment

\section{Production of viral particles using pBABE based retrovirus}

1) Trypsinize and seed one million HEK293-GP cells in a $10 \mathrm{~cm}$ dish and culture in CM using standard growth conditions.

2) After 24 hours cells are transfected with $5 \mu \mathrm{g}$ pBABE $+2 \mu \mathrm{g}$ pVSV-G using $17.5 \mu \mathrm{l}$ lipofectamine LTX (Invitrogen), according to manufacturer's instructions.

3) Incubate cells using standard growth conditions and replace medium with serum containing medium after 4 hours or overnight incubation.

4) Incubate cells for 3 days for viral particle production.

5) Harvest the medium directly from the cells and filter through a $0.45 \mu \mathrm{m}$ filter using a $10 \mathrm{ml}$ syringe to avoid cellular contaminants.

6) Aliquot $(1 \mathrm{ml})$ and freeze viral stocks at $-80^{\circ} \mathrm{C}$ in or use directly for infections.

\section{Infection of target cells}

7) Trypsinize and seed target cells into 2 wells of a 6-well plate, such that cells are at $30-40 \%$ confluence at time of infection.

8) Add $8 \mu \mathrm{g} / \mathrm{ml}$ polybrene immediately prior to virus addition.

9) Add $250 \mu \mathrm{l}$ viral stock from step 6) to one well and $750 \mu$ lo the second well. Add CM to a final volume of $1 \mathrm{ml}$.

10)After 24 hours of infection, replace medium with $\mathrm{CM}$.

11)Let cells proliferate until they reach confluency (at least 24 hours later).

12)Trypsinize cells, combine the 2 wells, and plate in a $10 \mathrm{~cm}$ dish containing the appropriate drug selection. We use pBABE vectors with Blasticidine S (Blast), puromycin or hygromycin resistance cassettes. E.g. HeLa cell clones are drug selected with $5 \mu \mathrm{g} / \mathrm{ml}$ Blast, 5 $\mu \mathrm{g} / \mathrm{ml}$ puromycin, or $250 \mathrm{\mu g} / \mathrm{ml}$ hygromycin.

13)Select cells until colonies are visible by the naked eye (10-20 days).

14)Trypsinize and pool the clones and amplify for single cell sorting.

15)To isolate monoclonal lines, cells are washed in sterile PBS, resuspended in sterile PBS $+5 \%$ BSA and sorted by standard flow sorting (using scatter to identify single cells) into 96-well plates containing conditioned culture medium (see Reagents and Solutions).

\section{Supporting Protocol 2}

\section{Cell Fixation and Immunofluorescence.}

In this section we describe a general method for fixation (of SNAP pulse labeled cells), immunofluorescence detection and DAPI staining. Immunofluorescence for detection of proteins unrelated to SNAP but localized at the same subcellular location allows for an 
independent measure to be used in image quantification using CraQ (see Basic Protocol 5, and Commentary). Please note that many other equally effective protocols for this purpose exist. As this is a general protocol we do not comment on specific antibody conditions and concentrations as this will need to be determined for each specific application.

\section{Materials}

- 1X PBS

- 4\% Paraformaldehyde in 1X PBS (Thermo Scientific), referred to as "PFA"

- $0.1 \mathrm{M}$ Tris-HCl, pH 7.5

- PBS-TX (1X PBS + 0.1\% Triton X-100)

- DAPI solution (see Reagents and Solutions)

- MOWIOL (see Reagents and Solutions)

- Nail polish

- Humid dark box (Can be made from an empty micropipette tip-box filled with a small layer of water, a thick sponge covered by a glass plate. Any transparent surface of the box is covered with aluminum foil.)

- Parafilm

- Clean, sterile, poly-lysine coated coverslips (12 mm ø; Thickness 1.5)

- Fine forceps with sharp pointed ends

- IF blocking buffer (see Reagents and Solutions)

- Standard glass slides

\section{Cell fixation}

1) Grow and SNAP pulse label cells on glass coverslips in 24-well plates as described in Basic Protocols 1-3.

2) Wash cells twice in $1 \mathrm{ml} P B S$, pre-heated to $37^{\circ} \mathrm{C}$.

3) Fix cells for exactly 10 minutes at room temperature in $500 \mu \mathrm{PFA}$, pre-heated to $37^{\circ} \mathrm{C}$.

4) Aspirate PFA and quench by adding $1 \mathrm{ml}$ of $0.1 \mathrm{M}$ Tris, pH 7.5 for 5 minutes. Cells can be stored at this point for up to a few days in $P B S$ at $4^{\circ} \mathrm{C}$, or up to 1 month in $P B S+0.04 \%$ $\mathrm{NaN}_{3}$ at $4^{\circ} \mathrm{C}$.

\section{Antibody detection}

5) Permeabilize cells by washing twice in $1 \mathrm{ml}$ of PBS-TX for 5 minutes.

6) Carefully lift coverslips with a forceps and move to a parafilm covered glass plate in humid dark box. Humid dark boxes prevent coverslips from drying and fluorescent dyes from photo-bleaching. Parafilm is a convenient receptacle for coverslips as its hydrophobic surface allows the application of small volumes to the coverslips without spilling over to neighboring coverslips.

7) Block cells for 30 minutes, $37^{\circ} \mathrm{C}$ in blocking buffer. Use $75 \mu \mathrm{l}$ per coverslip.

8) Incubate cells with primary antibody diluted in blocking buffer for 60 minutes, $37^{\circ} \mathrm{C}$. Use $30 \mu \mathrm{l}$ per coverslip.

9) Wash coverslips in $75 \mu$ PBS-TX 3 times for 5 minutes at room temperature.

10) Incubate secondary fluorescent antibody diluted in blocking buffer for 45 minutes, $37^{\circ} \mathrm{C}$. Use $30 \mu \mathrm{l}$ per coverslip. Centrifuge diluted fluorescent antibodies for 5 minutes at maximum speed $(\sim 16.000 \mathrm{~g})$ to deplete any fluorescent aggregates that may interfere with fluorescent imaging. Use supernatant for staining. 
11)Wash coverslips in $75 \mu$ PBS-TX 3 times for 5 minutes at room temperature.

12)Incubate cells in $50 \mu \mathrm{l}$ DAPI ( $500 \mathrm{ng} / \mathrm{ml}$ final concentration) for 5 minutes at room temperature.

13)Replace DAPI solution with PBS.

14)Carefully pick up coverslips with a forceps, remove excess liquid by aspiration and/or filter paper, and mount on a glass slide (cells facing down) in $\sim 5 \mu \mathrm{l} \mathrm{Mowiol.}$ Allow the Mowiol to solidify overnight at $4^{\circ} \mathrm{C}$ in the dark.

15)Seal coverslips using nail polish to avoid air contact during the imaging process.

\section{Reagents and Solutions}

-IF blocking buffer: $2 \%$ fetal bovine serum, $2 \%$ BSA, $0.1 \%$ Triton-X-100, $0.04 \% \mathrm{NaN}_{3}$, in $1 \mathrm{X}$ PBS.

- BTP (bromothenylpteridine): A $2 \mathrm{mM}$ stock is prepared by dissolving $100 \mathrm{nmol}$ lyophilized SNAP-Cell Block (New England Biolabs, cat\# S916S) in $50 \mu$ DMSO (sterile). Shake for 10 minutes in an eppendorf shaker at maximum speed to dissolve. Store for 1 month at $-20^{\circ} \mathrm{C}$ or aliquot and store at $-80^{\circ} \mathrm{C}$.

- Conditioned culture medium (for HeLa): 50\% fresh CM + 50\% CM harvested from HeLa cultures in log growth phase, $0.45 \mu \mathrm{M}$ filtered.

- DAPI(4',6-Diamidino-2-phenylindole dihydrochloride): A $1 \mathrm{mg} / \mathrm{ml}$ stock is prepared in water. Store at $-20^{\circ} \mathrm{C}$. Dilute 2000 fold in PBS for working solution.

-Live imaging medium: phenol red-free, $\mathrm{CO}_{2}$-independent medium (e.g. DME or Leibovitz's L-15) supplemented with 10\% fetal bovine serum, $2 \mathrm{mM}$ Glutamine (all from Gibco).

- MOWIOL:

Ingredients: Mowiol 4-88 (Calbiochem), Glycerol, DABCO (1,4-diazabicyclo[2.2.2]octane, Sigma)

1) Mix Mowiol 4-88 and glycerol in a 2:5 ratio (w/w).

2) Add $0.714 \mathrm{ml}$ water/gram of Mowiol/glycerol mixture and stir overnight at room temperature.

3) Add 2 volumes of $0.2 \mathrm{M}$ Tris ( $\mathrm{pH} 8.5$ ) for each volume of water added and heat at $50^{\circ} \mathrm{C}$ for 10 minutes with occasional mixing.

4) Centrifuge at $5.000 \mathrm{~g}$ for 15 minutes and remove debris.

5) Add DABCO to $2.4 \%$ and mix slowly.

6) Centrifuge at $5.000 \mathrm{~g}$ for 15 minutes and remove debris.

7) Aliquot and store at $-20^{\circ} \mathrm{C}$

- Standard culture medium (for HeLa and HEK293-GP): DMEM + 10\% NCS (newborn calf serum), $100 \mathrm{U} / \mathrm{ml}$ penicillin, $100 \mu \mathrm{g}$ of streptomycin, $2 \mathrm{mM}$ Glutamine (all from Gibco). Other cell types may require different growth media. 
- TMR-Star: A $200 \mu \mathrm{M}$ stock is prepared by dissolving $30 \mathrm{nmol}$ lyophilized SNAP-Cell TMRStar (New England Biolabs, cat \# S9105S) in $150 \mu$ DMSO (sterile). Shake for 10 minutes in an eppendorf shaker at maximum speed to dissolve. Store for 1 month at $-20^{\circ} \mathrm{C}$ or aliquot and store at $-80^{\circ} \mathrm{C}$.

- VALAP Vaseline (petroleum jelly): lanolin : paraffin 1:1:1 (w/w) (adapted from: Waterman-Storer and Salmon, 1997):

1) Heat paraffin to $50^{\circ} \mathrm{C}$ in a large beaker in a water bath.

2) When paraffin is melted mix in vaseline and lanolin.

3) Stir to mix and aliquot, store at $4^{\circ} \mathrm{C}$.

4) Heat to $50^{\circ} \mathrm{C}$ prior to use

\section{Commentary}

\section{Background Information}

Historical Background

The SNAP-tag is a modified version of human $0^{6}$-alkylguanine-DNA alkyltransferase (hAGT). Endogenous hAGT is a DNA repair enzyme that removes a broad range of alkyl adducts from the $0^{6}$ position of guanines in DNA. It acts as a suicide enzyme that catalyzes a covalent binding reaction between itself and the alkyl group that is removed from guanines, thereby restoring DNA integrity but inactivating its own catalytic activity (Pegg, 2000). SNAP, the modified form of hATG, has lost its affinity to DNA but efficiently reacts with soluble $0^{6}$-benzylguanine (BG), of which the benzyl moiety is readily transferred to the SNAP protein (Figure 1, Juillerat et al., 2003; Keppler et al., 2003). The benzyl rings in BG can be coupled to a large variety of molecules (Keppler et al., 2003, 2004, 2006) that include fluorescent moieties as well as non-fluorescent ones (a selection of SNAP substrates is presented in Table 2).

General considerations for SNAP-based protein turnover assays

A number of techniques exist to analyze protein turnover (Table 1). A common approach to in vivo protein turnover is the use of fluorescence recovery after photobleaching (FRAP). In this method, autofluorescent proteins are fused to proteins of interest that localize to a specific subcellular location. Local irreversible bleaching followed by repopulation of a bleached area by unbleached molecules from neighboring regions provides information of the local rate of protein turnover (Lippincott-Schwartz et al., 2001; and references therein). A reciprocal technique utilizes inducible fluorescent proteins, which can be activated by a focused laser, which allows tracking of a specific pool of photo-activated protein (Lukyanov et al., 2005; and references therein). While widely applied, FRAP and photo-activation experiments suffer from three specific drawbacks. 1) Measurement of fluorescence recovery or photoactivation typically requires continued imaging of cells, leading to problems such as photobleaching and phototoxicity, thereby restricting the time in which turnover can be measured to a few hours at most. This precludes measurement of longterm turnover rates. 2) A focused laser is required to bleach or activate fluorescence preventing the analysis of large numbers of cells simultaneously. Lastly 3), the turnover rates using FRAP and photo-activation are a product of the "on" and "off" rates of a protein 
which cannot be assessed separately. SNAP-based pulse labeling differs from traditional FRAP experiments in that a fluorescent pool is created by pulse labeling with the addition of an external dye to the culture medium. Therefore, first and foremost, imaging and quantification of its fluorescence can commence at any time following labeling (hours, days after pulse labeling). This allows analysis of protein turnover at very long time scales. Secondly, because the entire cell population is treated with the dye in bulk, large numbers of cells are available for simultaneous imaging and analysis. Lastly, the combination of serial dark and fluorescent pulse labeling strategies ("pulse-chase" and "quench-chasepulse") allows for the separate determination of turnover of pre existing pools (off-rates) and turnover of newly synthesized pools of protein (on-rates) (Figures 2-3).

Several other methods capitalize on similar advantages such as other self-labeling or destructive enzymes (see Table 1). We would like to highlight one recently developed method named "Recombination Induced Tag Exchange" (RITE), which allows for similar applications as SNAP-tagging while using a fundamentally different strategy (Verzijlbergen et al., 2010). It uses recombination induced switching of expression of differentially tagged versions of the same gene. This allows for the simultaneous visualization, tracking, and/or analysis of the original (pre-switched) pool as well as a nascent one (Radman-Livaja et al., 2011). However, this method relies on tight control over induction of Cre-mediated recombination which is difficult to achieve in some systems (most metazoan cell lines).

The advantage of assessing long-term dynamics also implies a major disadvantage of SNAPbased pulse labeling. Labeling and washing steps require approximately 1 hour rendering this method inappropriate to assess protein dynamics at short timescales (seconds to minutes), as pulse labeled proteins will have reached their steady state equilibrium before imaging can determine their dynamics. However, improvements are currently being made to both the SNAP-enzyme and the fluorescent substrates thereof, which would in principle allow labeling steps of 5 minutes without the need for any washes (see below and Sun et al., 2011).

\section{Critical Parameters and Troubleshooting}

SNAP Labeling

Choice of substrate - One very important parameter during the Pulse-Chase and QuenchChase-Pulse procedure in living cells is the choice of SNAP-substrate used. The limiting characteristic seems to be the ability of substrates to efficiently pass the cell membrane, as many substrates tend to strongly label the cell membrane while barely labeling intracellular SNAP proteins. In our experience, non-fluorescent benzylguanine (BG) or bromothenylpteridine (BTP) enter cells efficiently. However, addition of (bulky) side groups may impede the cell permeability.

Thus, although there is a large variety of fluorescent substrates for intra-cellular labeling, the efficiency at which these enter the cells is not always the same. For this reason, using the optimal fluorophore for the particular microscopy and filter setup used has to be balanced with the cell permeability of this substrate. We generally obtain the best results with SNAP-Cell TMR-Star (New England Biolabs).

It is for this reason that we prefer to use BTP for quench steps in the quench-chase-pulse procedures rather than using multiple different fluorescent substrates (see Basic Protocol 2), because complete labeling of the initial pool is essential to ensure visualization of the subsequent newly synthesized pool only. 
Of special interest are a group of recently developed SNAP-substrates that display a dramatic increase in fluorescence after reaction with SNAP. These so called 'dark-dyes' are either quenched by guanine itself (Stöhr et al., 2010), or by a side-group fused the guanine moiety of benzylguanine (Komatsu et al., 2011; Sun et al., 2011). These dark-dyes provide a number of advantages over traditional fluorescent SNAP-substrates, most importantly leading to highly reduced (unspecific) background fluorescence. Other advantages include wash-free labeling, faster downstream applications (due to shorter wash steps), and potentially more efficient live cell imaging.

In Table 2 we present a selection of (commercially available) SNAP substrates with their respective properties.

SNAP enzyme variants - Variants of SNAP have been derived by in vitro evolution. One example is the "CLIP-tag", which is derived from SNAP and reacts specifically with a variant substrate, $\mathrm{O}^{2}$-benzylcytosine (Gautier et al., 2008). Tagging of two different proteins by SNAP and CLIP allows for simultaneous labeling of two different proteins in different colors (Gautier et al., 2008; Prendergast et al., 2011). More recently, variants of SNAP and CLIP named SNAPf and CLIPf have been developed that present faster reaction kinetics (Pellett et al., 2011; Sun et al., 2011). We evaluated SNAPf and CLIPf performance in vivo by sideby-side comparison with SNAP and CLIP, using the intracellular protein CENP-A as a labeling target (data not shown and Figure 7A). While CLIPf showed only a modest improved over CLIP (not shown), SNAPf performed $\sim 3-5$ fold better across different concentrations of substrates and incubation times (Figure 7B). The use of SNAPf therefore allows for shorter labeling times and lower dye concentrations to yield the same signal intensity. A reduced background staining while retaining specific signals will potentially improve live cell capabilities significantly.

Dye concentration, wash steps and pool size - Depending on the cell type, SNAP protein fusion expression levels, particular SNAP-substrate, application, etc., it will be necessary to optimize the substrate concentration. More substrate is not necessarily better, because addition of substrate beyond saturation of labeling will result in more background labeling and thus poorer signal-to-noise ratios. For CENP-A-SNAP we generally use a concentration of $2 \mu \mathrm{M}$ TMR-Star as a compromise between signal-to-noise and cost (although we have found that using higher concentrations up to $5 \mu \mathrm{M}$ increases the signal-to-noise ratio of labeling). For other purposes it may be necessary to use saturating concentrations, or conversely, it may be sufficient to use lower concentrations.

We found that extensive washes after labeling ( 2 quick washes, an extended wash for 30 minutes at $37^{\circ} \mathrm{C}$, and two additional quick washes) help to remove excess unbound substrates. This results in dramatically decreased background fluorescence after pulse labeling. During quench labeling these wash steps ensure that nascent protein synthesized during the chase is not immediately quenched which would lower the effective poolside of the new pool and specific signals in subsequent fluorescent labeling.

Chase time - A critical aspect of a successful quench-chase-pulse experiment is the chase time that the cells are given to produce new protein. Although this is largely determined by the experimental conditions, one would typically seek conditions that maximizes the time for protein synthesis prior to labeling. 
Imaging and Quantification

For imaging of SNAP-derived and immunofluorescent signals any high resolution microscope can be used.

Marker used as reference - Special care should be taken to choose the marker used as a reference for spot detection. A number of options exist. 1) The signals that require quantification can be used simultaneously as a reference of spots to measure. However, this solution suffers from the drawback that spots with very low signals will not be detected and that the detection will be inherently biased, e.g. towards bright spots. A better option is to 2) use an antibody against SNAP (available from NEB) or HA (in case an HA-tag is incorporated in the fusion protein see Appendix 1), which will detect the entire pool of SNAP tagged protein independent of time sliced signals (see e.g. Figures 3B and 4B). However, if the protein of interest forms aggregates or has multiple possible localization patterns, these will also be quantified by automated methods such as CRaQ. Thus, whenever possible, we prefer to use 3) antibodies (or autofluorescent fusion proteins) against an independent marker for the subcellular structure (e.g. centromeres by CENP-C or CENP-T; see Figures 2B, 4C, and Silva et al., in press). This allows for specific and unbiased detection of spots. Naturally, clean references will lead to the most accurate quantifications and using antibodies that are highly specific and give little background staining will increase the quality of the data. In addition, when measuring proteins that reside inside the nucleus, an additional marker such as DAPI can be used to further exclude unspecific reference signals outside of the nucleus.

$C R a Q$ - There are a number of critical aspects to take into account when using CRaQ. First and foremost, as this is an automated algorithm, the results should be validated by the user. After initiating the macro one can follow the screen shots that pop up to monitor which spots are recognized as reference points. If the macro is poorly tuned it may already be obvious at this early stage (e.g. recognition of the entire image). Next, after completion of the macro, data output files should be checked to validate whether the correct spots are detected (e.g. by doing this manually for a small, random subset of pictures and comparing this to the spots recognized automatically). If automated spot recognition is not accurate, the parameters should be optimized as described in Basic Protocol 5. Parameter optimization and testing is best done on a small subset of pictures to save time.

Evidently, using a high-end microscope with appropriate filter combinations and a sensitive camera is instrumental to obtain good fluorescence quantifications. In addition, potential chromatic aberrations between reference and data channels must be corrected for in the quantification (this can also be set as a parameter of $\mathrm{CRaQ}$ ). One way to determine the chromatic aberration is to use beads that are fluorescent in the two channels used and determine whether and by how many pixels the center of mass is shifted between the colors.

Finally, although inorganic dyes are generally very photostable, we have observed that imaging TMR-Star labeled cells as soon as possible after fixation (1-2 days) facilitates obtaining the most optimal signals.

\section{Anticipated Results}




\section{SNAP-labeling}

Because SNAP substrates are added to the culture medium, virtually all SNAP-expressing cells are labeled in any given experiment. The ability to detect SNAP-tagged proteins depends on the expression level of the protein and the efficiency of SNAP substrate entry into the cells. In quench-chase-pulse experiments, the chase time during which cells synthesize and assemble new protein will determine which cells will become labeled during the second, fluorescent labeling step. In the case of CENP-A-SNAP, the appearance of centromeric signals will largely depend on cell cycle position (Figure 4B and 5). The expected results for other proteins will depend on the biological properties of the protein of interest.

Many SNAP-substrates have difficulty passing through the cell membrane. For this reason it is normal to see relatively high background fluorescence, as compared to e.g. antibody or fluorescent protein detection. We try to minimize this background fluorescence by extensive washes of the fluorescent substrate after labeling is completed (steps e.g. 5-6 of Basic Protocol 1).

\section{Image quantification}

Using CRaQ we generally have very low false-positive rates, where off-target sites or doublets comprise $\ll 1 \%$ of all spots detected. In addition, this macro is generally able to detect a good proportion of the correct spots to be analyzed (>50\%), although this largely depends on the quality of the reference signal. Using a generic present day desktop computer we can readily collect hundreds to thousands of data points in 15-20 minutes. The rate limiting steps are testing parameter settings (although generic parameter settings usually work very well) and analyzing the data generated.

\section{Time Considerations}

The time that is required for the experiments outlined above is highly variable and depends on the precise setup of the experiment. Quench and Pulse labeling each take about 1-1.5h to perform. However, the chase time can be anywhere between a few hours and a few days. Furthermore, adding sequential steps, such as synchronization and/or RNAi procedures can increase the total time of the experiment to more than a week. Fixation and antibody labeling requires approximately 4-5 hours to perform and cells are preferentially imaged on the following day. Imaging requires roughly 30 minutes per coverslip used, although this again depends on many factors, including the microscopy system, signal intensity (i.e. exposure times needed), cell density (i.e. number of images required), sample thickness (i.e. number of slices required), etc. Running $\mathrm{CRaQ}$ generally takes no more than 20 minutes, even for large datasets, and validation of the output takes about the same time. Finally, processing of the output data into comprehensible tables/graphs takes about 30 minutes to 1 hour, depending on the size of the dataset.

\section{Acknowledgements}

We thank Mariana Silva for valuable comments on the manuscript. DLB and MGR are supported by the Fundação para a Ciência e a Tecnologia (FCT) doctoral fellowships SFRH/BD/74284/2010 and SFRH/BD/33567/2008, respectively. This work is supported 
by the Fundação Calouste Gulbenkian, FCT grants BIA-BCM/100557/2008 and BIAPRO/100537/2008, the European Commission FP7 programme, and an EMBO installation grant to LETJ.

\section{Literature cited}

Banala, S., Arnold, A., and Johnsson, K. 2008. Caged substrates for protein labeling and immobilization. Chembiochem: A European Journal of Chemical Biology 9:38-41.

Bojkowska, K., Santoni de Sio, F., Barde, I., Offner, S., Verp, S., Heinis, C., Johnsson, K., and Trono, D. 2011. Measuring in vivo protein half-life. Chemistry \& Biology 18:805-815.

Burns, J. C., Friedmann, T., Driever, W., Burrascano, M., and Yee, J. K. 1993. Vesicular stomatitis virus $\mathrm{G}$ glycoprotein pseudotyped retroviral vectors: concentration to very high titer and efficient gene transfer into mammalian and nonmammalian cells. Proceedings of the National Academy of Sciences of the United States of America 90:8033-8037.

Campos, C., Kamiya, M., Banala, S., Johnsson, K., and González-Gaitán, M. 2011. Labelling cell structures and tracking cell lineage in zebrafish using SNAP-tag. Developmental Dynamics: An Official Publication of the American Association of Anatomists 240:820827.

Damoiseaux, R., Keppler, A., and Johnsson, K. 2001. Synthesis and applications of chemical probes for human 06-alkylguanine-DNA alkyltransferase. Chembiochem: A European Journal of Chemical Biology 2:285-287.

Deal, R. B., Henikoff, J. G., and Henikoff, S. 2010. Genome-wide kinetics of nucleosome turnover determined by metabolic labeling of histones. Science (New York, N.Y.) 328:1161-1164.

Dellagiacoma, C., Lukinavičius, G., Bocchio, N., Banala, S., Geissbühler, S., Märki, I., Johnsson, K., and Lasser, T. 2010. Targeted Photoswitchable Probe for Nanoscopy of Biological Structures. ChemBioChem 11:1361-1363.

Dunleavy, E. M., Almouzni, G., and Karpen, G. H. 2011. H3.3 is deposited at centromeres in S phase as a placeholder for newly assembled CENP-A in G(1) phase. Nucleus (Austin, Tex.) 2:146-157.

Engin, S., Trouillet, V., Franz, C. M., Welle, A., Bruns, M., and Wedlich, D. 2010. Benzylguanine Thiol Self-Assembled Monolayers for the Immobilization of SNAP-tag Proteins on Microcontact-Printed Surface Structures. Langmuir 26:6097-6101.

Erhardt, S., Mellone, B. G., Betts, C. M., Zhang, W., Karpen, G. H., and Straight, A. F. 2008. Genome-wide analysis reveals a cell cycle-dependent mechanism controlling centromere propagation. The Journal of Cell Biology 183:805-818. 
Gallagher, S. S., Sable, J. E., Sheetz, M. P., and Cornish, V. W. 2009. An in vivo covalent TMPtag based on proximity-induced reactivity. ACS chemical biology 4:547-556.

Gautier, A., Juillerat, A., Heinis, C., Corrêa, I. R., Kindermann, M., Beaufils, F., and Johnsson, K. 2008. An engineered protein tag for multiprotein labeling in living cells. Chemistry \& Biology 15:128-136.

Hussain, A. F., Kampmeier, F., von Felbert, V., Merk, H.-F., Tur, M. K., and Barth, S. 2011. SNAP-Tag Technology Mediates Site Specific Conjugation of Antibody Fragments with a Photosensitizer and Improves Target Specific Phototoxicity in Tumor Cells. Bioconjugate Chem. Available at: http://dx.doi.org/10.1021/bc200304k.

Jansen, L. E. T., Black, B. E., Foltz, D. R., and Cleveland, D. W. 2007. Propagation of centromeric chromatin requires exit from mitosis. The Journal of Cell Biology 176:795-805.

Juillerat, A., Gronemeyer, T., Keppler, A., Gendreizig, S., Pick, H., Vogel, H., and Johnsson, K. 2003. Directed evolution of 06-alkylguanine-DNA alkyltransferase for efficient labeling of fusion proteins with small molecules in vivo. Chemistry \& Biology 10:313317.

Keppler, A., Arrivoli, C., Sironi, L., and Ellenberg, J. 2006. Fluorophores for live cell imaging of AGT fusion proteins across the visible spectrum. BioTechniques 41:167-170, 172, 174-175.

Keppler, A., Gendreizig, S., Gronemeyer, T., Pick, H., Vogel, H., and Johnsson, K. 2003. A general method for the covalent labeling of fusion proteins with small molecules in vivo. Nature Biotechnology 21:86-89.

Keppler, A., Pick, H., Arrivoli, C., Vogel, H., and Johnsson, K. 2004. Labeling of fusion proteins with synthetic fluorophores in live cells. Proceedings of the National Academy of Sciences of the United States of America 101:9955-9959.

Komatsu, T., Johnsson, K., Okuno, H., Bito, H., Inoue, T., Nagano, T., and Urano, Y. 2011. Realtime measurements of protein dynamics using fluorescence activation-coupled protein labeling method. Journal of the American Chemical Society 133:6745-6751.

Lin, M. Z., Glenn, J. S., and Tsien, R. Y. 2008. A drug-controllable tag for visualizing newly synthesized proteins in cells and whole animals. Proceedings of the National Academy of Sciences 105:7744.

Lippincott-Schwartz, J., Snapp, E., and Kenworthy, A. 2001. Studying protein dynamics in living cells. Nat Rev Mol Cell Biol 2:444-456.

Los, G. V., and Wood, K. 2007. The HaloTag: a novel technology for cell imaging and protein analysis. Methods in Molecular Biology (Clifton, N.J.) 356:195-208. 
Lukyanov, K. A., Chudakov, D. M., Lukyanov, S., and Verkhusha, V. V. 2005. Innovation: Photoactivatable fluorescent proteins. Nature Reviews. Molecular Cell Biology 6:885891.

Maduzia, L. L., Yu, E., and Zhang, Y. 2010. Caenorhabditis elegans Galectins LEC-6 and LEC10 Interact with Similar Glycoconjugates in the Intestine. Journal of Biological Chemistry 286:4371-4381.

Maurel, D., Banala, S., Laroche, T., and Johnsson, K. 2010. Photoactivatable and photoconvertible fluorescent probes for protein labeling. ACS Chemical Biology 5:507-516.

McMurray, M. A., and Thorner, J. 2008. Septin stability and recycling during dynamic structural transitions in cell division and development. Current Biology: CB 18:12031208.

Morgenstern, J. P., and Land, H. 1990. Advanced mammalian gene transfer: high titre retroviral vectors with multiple drug selection markers and a complementary helper-free packaging cell line. Nucleic Acids Research 18:3587 -3596.

Nishimura, K., Fukagawa, T., Takisawa, H., Kakimoto, T., and Kanemaki, M. 2009. An auxinbased degron system for the rapid depletion of proteins in nonplant cells. Nat Meth 6:917-922.

O'Hare, H. M., Johnsson, K., and Gautier, A. 2007. Chemical probes shed light on protein function. Current Opinion in Structural Biology 17:488-494.

Ong, S.-E., Blagoev, B., Kratchmarova, I., Kristensen, D. B., Steen, H., Pandey, A., and Mann, M. 2002. Stable isotope labeling by amino acids in cell culture, SILAC, as a simple and accurate approach to expression proteomics. Molecular \& Cellular Proteomics: MCP 1:376-386.

Pegg, A. E. 2000. Repair of O(6)-alkylguanine by alkyltransferases. Mutation Research 462:83-100.

Pellett, P. A., Sun, X., Gould, T. J., Rothman, J. E., Xu, M.-Q., Corrêa, I. R., and Bewersdorf, J. 2011. Two-color STED microscopy in living cells. Biomedical Optics Express 2:23642371.

Prendergast, L., van Vuuren, C., Kaczmarczyk, A., Doering, V., Hellwig, D., Quinn, N., Hoischen, C., Diekmann, S., and Sullivan, K. F. 2011. Premitotic assembly of human CENPs -T and -W switches centromeric chromatin to a mitotic state. PLoS Biology 9:e1001082.

Radman-Livaja, M., Verzijlbergen, K. F., Weiner, A., van Welsem, T., Friedman, N., Rando, 0. J., and van Leeuwen, F. 2011. Patterns and Mechanisms of Ancestral Histone Protein Inheritance in Budding Yeast. PLoS Biol 9:e1001075. 
Silva, M. C. C., Bodor, D. L., Stellfox, M. E., Martins, N. M. C., Hochegger, H., Foltz, D. R., and Jansen, L. E. T. in press. Cdk Activity Couples Epigenetic Centromere Inheritance to Cell Cycle Progression. Developmental Cell.

Stöhr, K., Siegberg, D., Ehrhard, T., Lymperopoulos, K., Öz, S., Schulmeister, S., Pfeifer, A. C., Bachmann, J., Klingmüller, U., Sourjik, V., et al. 2010. Quenched substrates for livecell labeling of SNAP-tagged fusion proteins with improved fluorescent background. Analytical Chemistry 82:8186-8193.

Sullivan, K. F., Hechenberger, M., and Masri, K. 1994. Human CENP-A contains a histone H3 related histone fold domain that is required for targeting to the centromere. The Journal of Cell Biology 127:581-592.

Sun, X., Zhang, A., Baker, B., Sun, L., Howard, A., Buswell, J., Maurel, D., Masharina, A., Johnsson, K., Noren, C. J., et al. 2011. Development of SNAP-Tag Fluorogenic Probes for Wash-Free Fluorescence Imaging. Chembiochem 12:2217-2226.

Verzijlbergen, K. F., Menendez-Benito, V., Van Welsem, T., Van Deventer, S. J., Lindstrom, D. L., Ovaa, H., Neefjes, J., Gottschling, D. E., and Van Leeuwen, F. 2010. Recombinationinduced tag exchange to track old and new proteins. Proceedings of the National Academy of Sciences 107:64.

Waterman-Storer, C. M., and Salmon, E. D. 1997. Actomyosin-based Retrograde Flow of Microtubules in the Lamella of Migrating Epithelial Cells Influences Microtubule Dynamic Instability and Turnover and Is Associated with Microtubule Breakage and Treadmilling. The Journal of Cell Biology 139:417 -434.

Yang, P.-Y., Liu, K., Zhang, C., Chen, G. Y. J., Shen, Y., Ngai, M. H., Lear, M. J., and Yao, S. Q. 2011. Chemical Modification and Organelle-Specific Localization of Orlistat-Like Natural-Product-Based Probes. Chemistry - An Asian Journal 6:2762-2775.

Yee, J. K., Miyanohara, A., LaPorte, P., Bouic, K., Burns, J. C., and Friedmann, T. 1994. A general method for the generation of high-titer, pantropic retroviral vectors: highly efficient infection of primary hepatocytes. Proceedings of the National Academy of Sciences 91:9564 -9568.

\section{Key References (optional)}

Jansen, L. E. T., Black, B. E., Foltz, D. R., and Cleveland, D. W. 2007. Propagation of centromeric chromatin requires exit from mitosis. The Journal of Cell Biology 176:795-805.

Keppler, A., Gendreizig, S., Gronemeyer, T., Pick, H., Vogel, H., and Johnsson, K. 2003. A general method for the covalent labeling of fusion proteins with small molecules in vivo. Nature Biotechnology 21:86-89.

\section{Internet Resources}


ImageJ software and Grouped_ZProjector plugin (http://rsbweb.nih.gov/ij/index.html). CRaQ macro for ImageJ (http://uic.igc.gulbenkian.pt/micro-macros.htm).

\section{Figure Legends}

Figure 1. Principle of SNAP pulse labeling. SNAP is cloned as an epitope tag to a protein of interest. Reaction of SNAP fusion proteins with benzylguanine (or labeled derivatives) results in a covalent irreversible bond between the (labeled) benzyl moiety and a reactive cysteine in SNAP.

Figure 2. Pulse-chase imaging. (A) Schematic outlining an in vivo SNAP pulse labeling strategy (Basic Protocol 1). Cells that produce and turnover SNAP-tagged protein are incubated with the SNAP substrate TMR-Star (Pulse) at time $\mathrm{T}_{0}$, rendering the available cellular pool of SNAP fluorescent. Following substrate washout (chase), cells continue to synthesize SNAP protein (light blue) that is not labeled while the pulse labeled pool turns over. The remaining fluorescently pulse labeled pool of SNAP can be visualized and quantified at various time points $\left(\mathrm{T}_{\mathrm{n}}\right)$ during the chase by microscopy. (B) Example of a pulse-chase experiment using cells expressing CENP-A-SNAP. CENP-A (top panels) localizes to centromeres that are visualized as subnuclear, diffraction limited foci. CENP-A-SNAP is pulse labeled at $0 \mathrm{~h}$ with TMR-Star after which cells are chased and the remaining pulse labeled pool is visualized by high magnification microscopy at indicated time points. After 72 hours a small but detectable pool of CENP-A-SNAP is still present at centromeres (inset at 72h shows rescaled CENP-A::TMR-Star and CENP-C signals). Cells were counterstained with CENP-C (green) and DAPI (blue) to visualize centromeres and DNA, respectively.

Figure 3. Quench-Chase-Pulse imaging. (A) Schematic outlining an in vivo SNAP QuenchChase-Pulse labeling strategy (Basic Protocol 2). Cells that produce and turnover SNAPtagged protein are incubated with a non fluorescent SNAP substrate BTP (Quench) at time $\mathrm{T}_{0}$, rendering the available cellular pool unavailable for subsequent fluorescent labeling (dark blue). Following substrate washout (chase), cells continue to synthesize SNAP protein (light blue) that is not labeled. After a set chase time, nascent protein is specifically labeled with TMR-Star. This nascent (new) fluorescent pool of SNAP can be visualized and quantified at various time points $\left(\mathrm{T}_{n}\right)$ during the subsequent chase by microscopy. (B) Quench-Pulse control. Cells expressing CENP-A-SNAP were either pulse labeled with TMRStar (Pulse) or quenched with BTP immediately preceding the pulse labeling step (QuenchPulse) followed by immunofluorescence and imaging. While pulse labeling results in fluorescent centromeric CENP-A-SNAP, pre-incubation of cells with BTP (Quench) renders this pool undetectable. Cells are counterstained with anti-HA, which detects the total pool of (CENP-A-) SNAP. The merged image shows TMR-Star (green) and HA (red) signals together with DAPI stain (blue). (C) Cells expressing CENP-A-SNAP were subjected to a quench-chase-pulse experiment as outlined in (A), processed for immunofluorescence and imaged. Nascent CENP-A-SNAP (green) localizes to centromeres only in a subset of cells (arrow) while remaining non-centromeric in others (arrow heads) highlighting a cell cycle dependence in nascent CENP-A-SNAP dynamics (Jansen et al., 2007). Cells are counterstained with anti-tubulin (red) and DAPI (blue) to visualize microtubules and DNA, 
respectively. (D) Experiment as in (C) except that cells expressing SNAP-tagged histone H3.1 were subjected to the quench-chase-pulse protocol. H3.1 is a canonical histone that assembles into chromatin in S-phase. Cells that either do not assemble (arrowhead) or are in various stages of nascent histone H3.1 (red) assembly (arrows) are shown. Cells are counterstained with DAPI to visualize DNA (blue). Panels (B) and (C) are adapted from Jansen et al., 2007.

Figure 4. Combined strategies of SNAP labeling, cell synchronization and RNAi. (A) Schematic outline of quench-chase-pulse protocol combined with cell synchronization using double thymidine arrest and RNAi as described in Basic Protocol 3. (B) Combining quench-chase-pulse labeling with cell synchronization. Cells expressing CENP-A-SNAP and arrested at the G1/S boundary by double thymidine arrest (as in A) were treated with BTP to quench available SNAP pools followed by release into S-phase during which new CENPA-SNAP was synthesized. The nascent CENP-A-SNAP pool was pulse labeled with TMR-Star after a 7 hour chase at the end of S-phase. Cells were fixed at different time points to sample the population for centromere localization of nascent CENP-A-SNAP in S, G2, mitosis (M) and G1-phase cells. While the nascent pool is labeled at 7 hours post release, it does not localize to the centromere until cells reach G1-phase. Cells are counterstained with anti-HA, which detects the total pool of (CENP-A-) SNAP. The merged image shows TMR-Star (green) and HA (red) signals together with DAPI stain (blue). (C) Combining quench-chase-pulse and pulse-chase labeling with RNAi. An asynchronous population of cells expressing CENP-A-SNAP were transfected with siRNAs to block synthesis of nascent CENP-A or of a control protein (GAPDH). Cells were then either pulse-chase labeled (left) or quench-chase-pulse labeled (right) at indicated time points and assayed 48 hours after siRNA addition to determine the fate of old and new pools of protein, respectively. CENP-ASNAP::TMR-Star signals representing old and new protein pools are shown following RNAi. Cells were counterstained with CENP-C (green) and DAPI (blue) to visualize centromeres and DNA, respectively. TMR-Star centromere intensity levels at the centromere were determined by CRaQ (Basic Protocol 5). Average centromeric CENP-A-SNAP::TMR-Star signals were determined from 3 replicate experiments. Signals after GAPDH RNAi were set to 1 . Error bars indicate standard error of the mean (SEM). While CENP-A RNAi impairs the synthesis and accumulation of nascent CENP-A (new pool) the pool synthesized prior to siRNA addition is unaffected, demonstrating the ability to differentially visualize old and new protein pools. Panel (B) is adapted from Jansen et al., 2007.

Figure 5. Live cell imaging of SNAP labeled cells. Schematic outlines cell synchronization and quench-chase-pulse labeling steps as shown in Figure 4B. Following pulse labeling, cells are cycled into mitosis and mounted for live cell imaging (Basic Protocol 4). Time lapse series is shown of a cell in mitosis. At early time points, TMR-Star signals are noncentromeric, but are observed near the cell periphery, probably reflecting non-specific retention of the fluorescent substrate in cellular membranes. As cells exit from mitosis (after anaphase, $\mathrm{t}=0$ minutes) TMR-Star signal accumulates at centromeres from $\mathrm{t}=50$ minutes onwards. Cells express GFP-CENP-C that constitutively labels centromeres throughout the experiment. Insets show colocalization of nascent CENP-A-SNAP::TMR-Star (green) with centromeres (CENP-C, red). Image is adapted from Jansen et al., 2007. 
Figure 6. Centromere Recognition and Quantification (CRaQ). (A-E) Flow-scheme outlining automated steps of centromere recognition by CRaQ (Basic Protocol 5). (A) DAPI images are thresholded and converted to binary images (mask). (B) REFERENCE images are filtered and (C) overlaid with the mask to produce a masked reference image. (D) This image is again thresholded and spots that fit with the given parameter settings are exported as regions of interest (rois). (E) DATA images are measured at each roi. The blowup shows accuracy and frequency of centromere recognition. Note that raw data images are indicated by capitals, while processed images are indicated by lowercase letters in A-E. (F) CRaQ was used to re-analyze measurements that were performed by manual selection and quantification in Jansen et al., 2007. The two methods result in practically identical quantifications, thus cross-validating both methods. (G) Replicate samples were analyzed by CRaQ and standard error of mean (SEM) is plotted as a percentage of the average value for four independent experiments, each consisting of four replicate samples.

Figure 7. Evaluation of SNAPf-tag performance. (A) HeLa cells were transfected with either CENP-A-SNAP or CENP-A-SNAPf fusion proteins, and labeled with TMR-Star at different concentrations and incubation times, as indicated in the figure. Representative images of cells are shown with TMR-Star signals in green and DAPI (DNA) in blue. (B) TMR-Star and HA fluorescence intensity were determined using CRaQ (Basic Protocol 5) and TMR-Star/HA ratios are used as a measure of SNAP or SNAPf activity. Results are plotted as fold difference, normalized to signals obtained with SNAP after incubation with $2 \mu \mathrm{M}$ TMR-Star for 15 minutes (standard conditions). SNAPf outperforms SNAP in all conditions tested (3-5 fold).

\section{Tables}

Table 1. Methods to analyze protein turnover.

Table 2. Selection of SNAP-substrates.

\section{Appendices}

Appendix 1. Maps of SNAP- and SNAPf-tags.

Appendix 2. CRaQ macro for ImageJ.

\section{Copyright Permissions}




\section{Bodor et al., Figure 1}
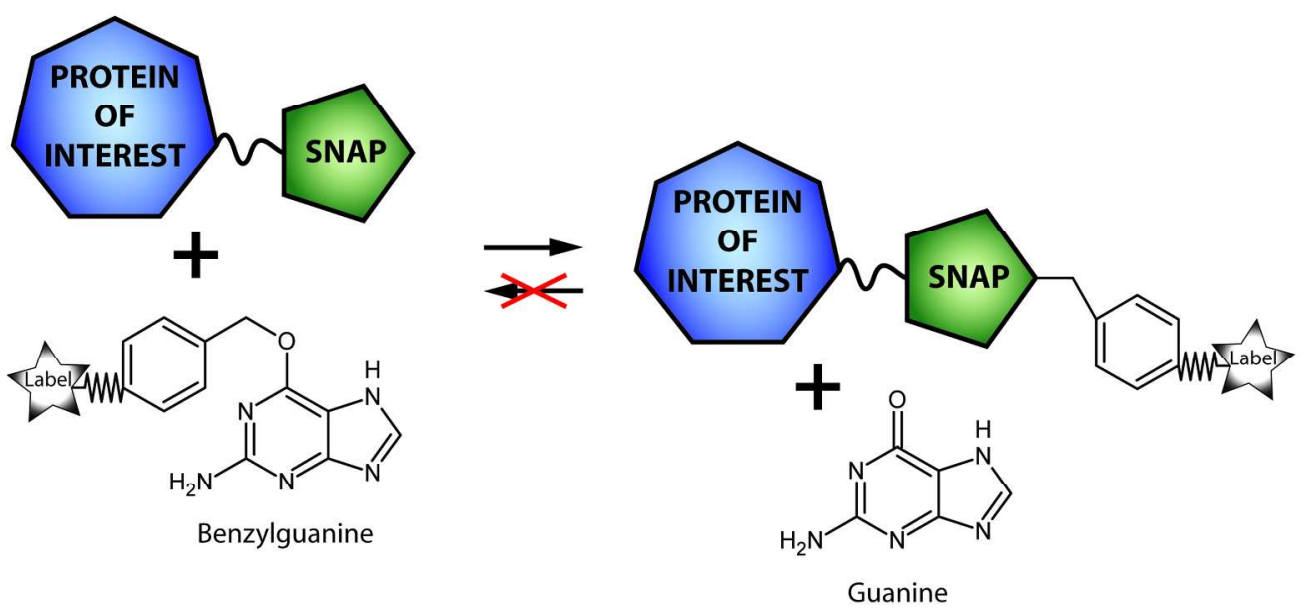

Figure 1. Principle of SNAP pulse labeling. SNAP is cloned as an epitope tag to a protein of interest. Reaction of SNAP fusion proteins with benzylguanine (or labeled derivatives) results in a covalent irreversible bond between the (labeled) benzyl moiety and a reactive cysteine in SNAP. $194 \times 112 \mathrm{~mm}(300 \times 300 \mathrm{DPI})$ 
A
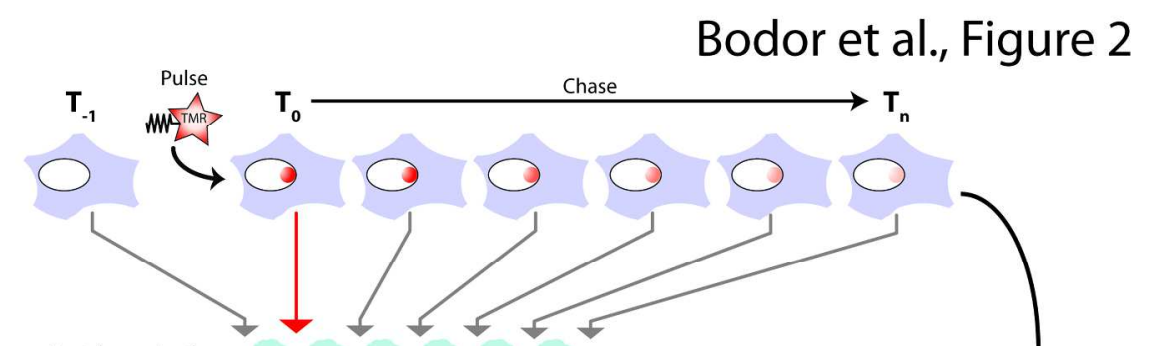
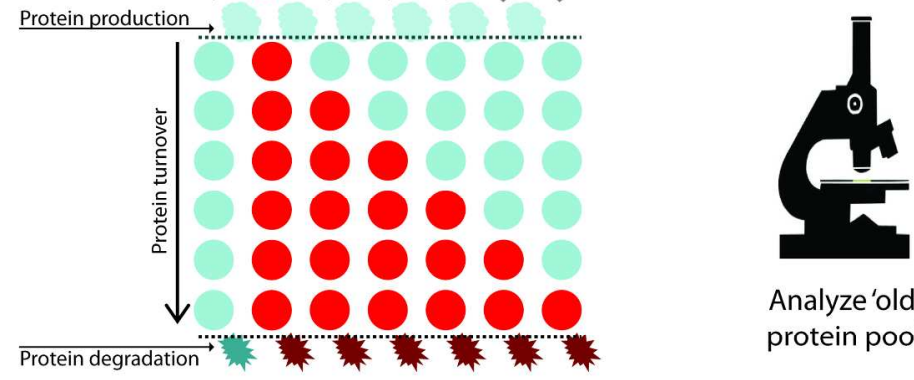

Analyze'old' protein pool

\section{B}
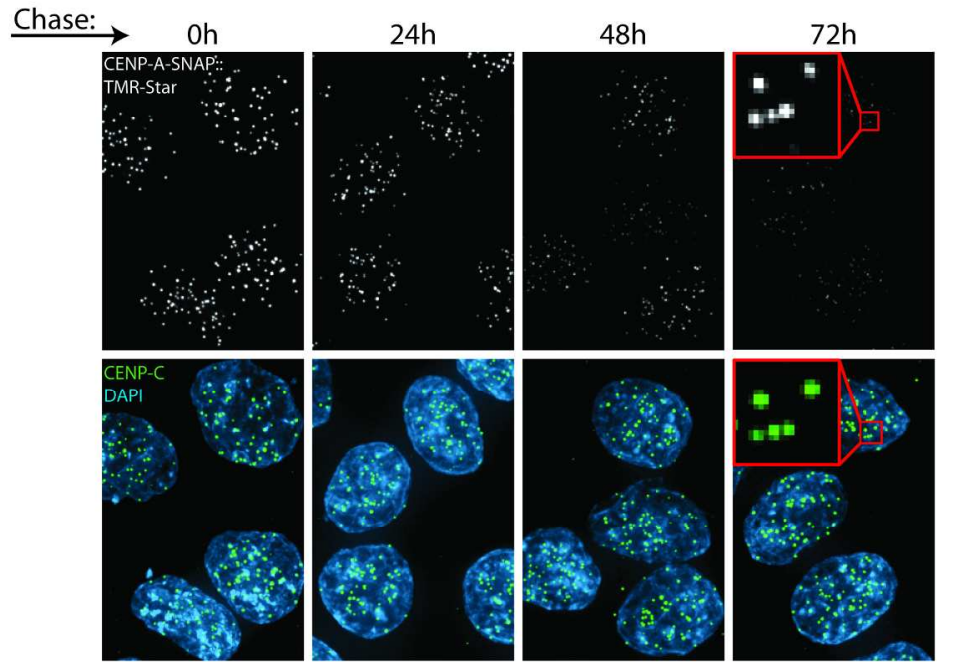

Figure 2. Pulse-chase imaging. (A) Schematic outlining an in vivo SNAP pulse labeling strategy (Basic Protocol 1). Cells that produce and turnover SNAP-tagged protein are incubated with the SNAP substrate TMR-Star (Pulse) at time $T_{0}$, rendering the available cellular pool of SNAP fluorescent. Following substrate washout (chase), cells continue to synthesize SNAP protein (light blue) that is not labeled while the pulse labeled pool turns over. The remaining fluorescently pulse labeled pool of SNAP can be visualized and quantified at various time points $\left(T_{n}\right)$ during the chase by microscopy. (B) Example of a pulse-chase experiment using cells expressing CENP-A-SNAP. CENP-A (top panels) localizes to centromeres that are visualized as subnuclear, diffraction limited foci. CENP-A-SNAP is pulse labeled at Oh with TMR-Star after which cells are chased and the remaining pulse labeled pool is visualized by high magnification microscopy at indicated time points. After 72 hours a small but detectable pool of CENP-A-SNAP is still present at

centromeres (inset at $72 \mathrm{~h}$ shows rescaled CENP-A::TMR-Star and CENP-C signals). Cells were counterstained with CENP-C (green) and DAPI (blue) to visualize centromeres and DNA, respectively. $213 \times 246 \mathrm{~mm}(300 \times 300 \mathrm{DPI})$ 


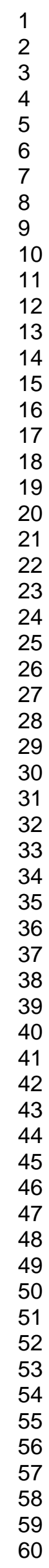




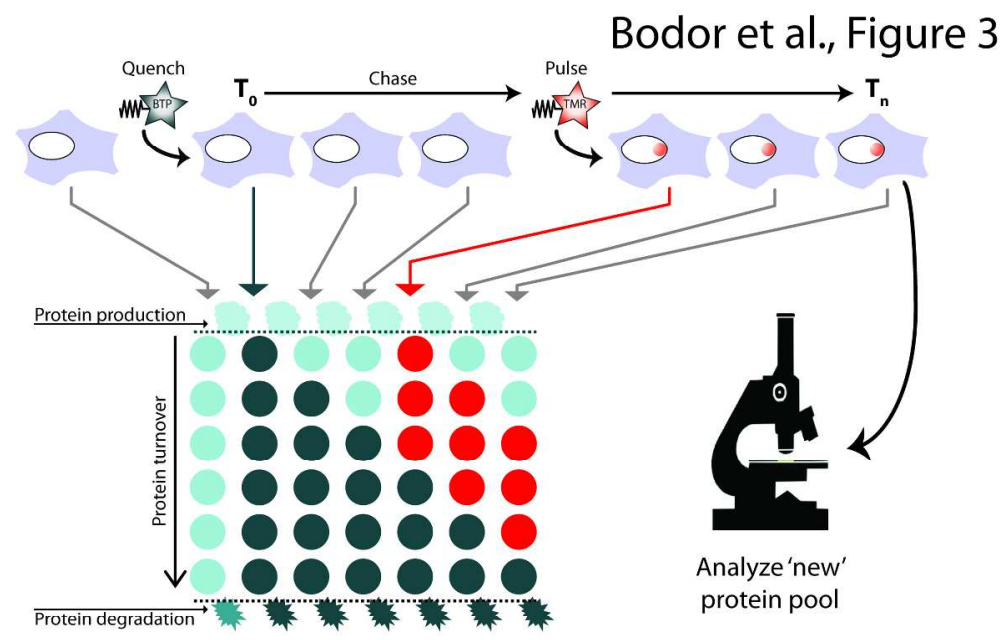

B

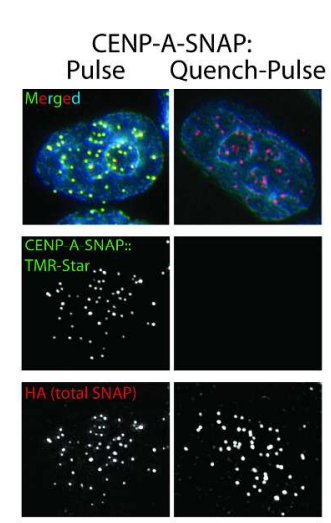

C

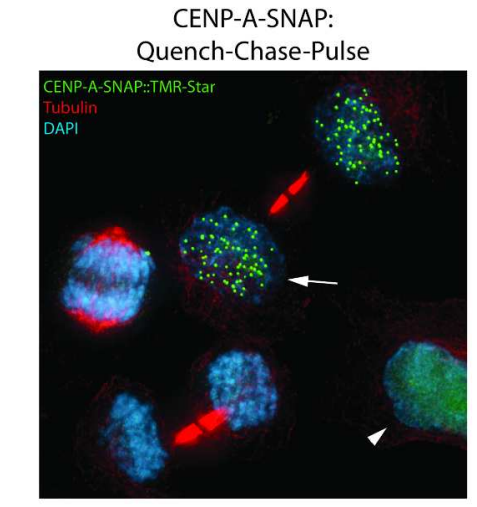

D
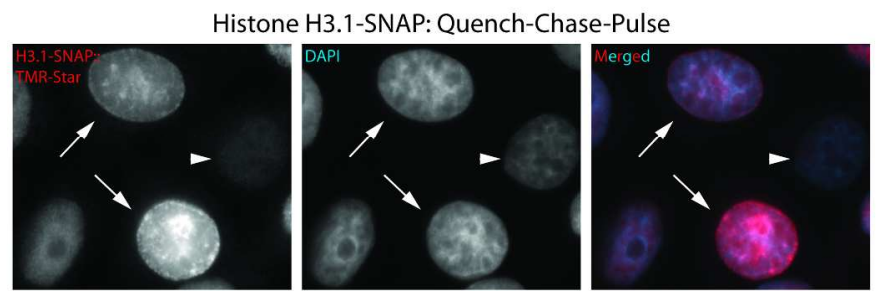

Figure 3. Quench-Chase-Pulse imaging. (A) Schematic outlining an in vivo SNAP Quench-Chase-Pulse labeling strategy (Basic Protocol 2). Cells that produce and turnover SNAP-tagged protein are incubated with a non fluorescent SNAP substrate BTP (Quench) at time $T_{0}$, rendering the available cellular pool unavailable for subsequent fluorescent labeling (dark blue). Following substrate washout (chase), cells continue to synthesize SNAP protein (light blue) that is not labeled. After a set chase time, nascent protein is specifically labeled with TMR-Star. This nascent (new) fluorescent pool of SNAP can be visualized and quantified at various time points $\left(T_{n}\right)$ during the subsequent chase by microscopy. (B) Quench-Pulse control. Cells expressing CENP-A-SNAP were either pulse labeled with TMR-Star (Pulse) or quenched with BTP immediately preceding the pulse labeling step (Quench-Pulse) followed by immunofluorescence and imaging. While pulse labeling results in fluorescent centromeric CENP-A-SNAP, pre-incubation of cells with BTP (Quench) renders this pool undetectable. Cells are counterstained with anti-HA, which detects the total pool of (CENP-A-) SNAP. The merged image shows TMR-Star (green) and HA (red) signals together with DAPI stain (blue). (C) Cells expressing CENP-A-SNAP were subjected to a quench-chase-pulse experiment as outlined in (A), 
processed for immunofluorescence and imaged. Nascent CENP-A-SNAP (green) localizes to centromeres only in a subset of cells (arrow) while remaining non-centromeric in others (arrow heads) highlighting a cell cycle dependence in nascent CENP-A-SNAP dynamics (Jansen et al., 2007). Cells are counterstained with antitubulin (red) and DAPI (blue) to visualize microtubules and DNA, respectively. (D) Experiment as in (C) except that cells expressing SNAP-tagged histone H3.1 were subjected to the quench-chase-pulse protocol. H3.1 is a canonical histone that assembles into chromatin in S-phase. Cells that either do not assemble (arrowhead) or are in various stages of nascent histone H3.1 (red) assembly (arrows) are shown. Cells are counterstained with DAPI to visualize DNA (blue). Panels (B) and (C) are adapted from Jansen et al., 2007. $205 \times 287 \mathrm{~mm}(300 \times 300$ DPI) 


\section{A}

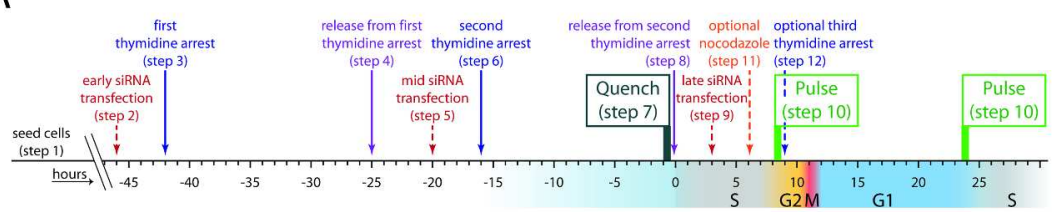

B
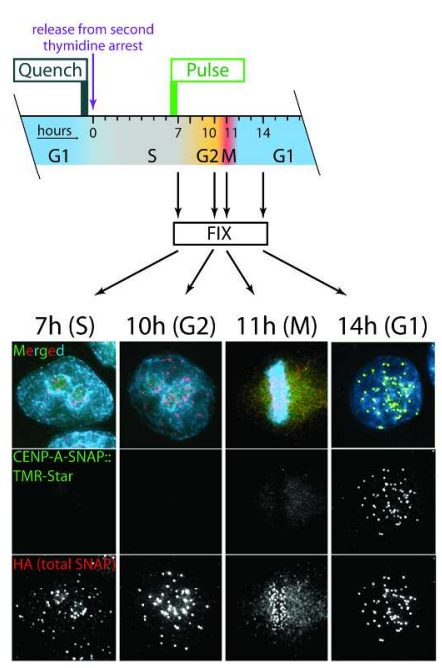

C
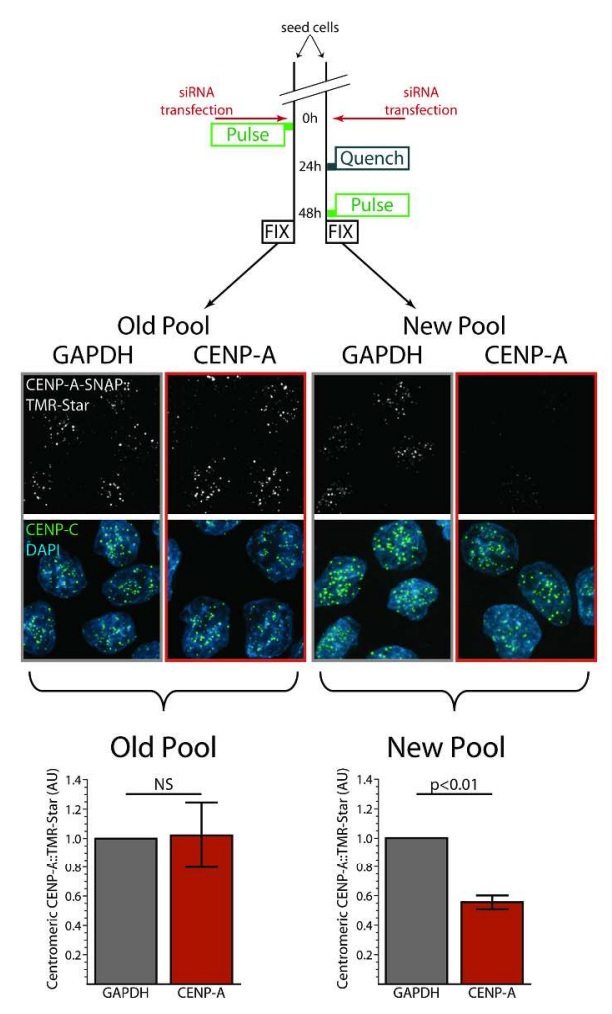

Figure 4. Combined strategies of SNAP labeling, cell synchronization and RNAi. (A) Schematic outline of quench-chase-pulse protocol combined with cell synchronization using double thymidine arrest and RNAi as described in Basic Protocol 3. (B) Combining quench-chase-pulse labeling with cell synchronization. Cells expressing CENP-A-SNAP and arrested at the G1/S boundary by double thymidine arrest (as in A) were treated with BTP to quench available SNAP pools followed by release into S-phase during which new CENP-A-SNAP was synthesized. The nascent CENP-A-SNAP pool was pulse labeled with TMR-Star after a 7 hour chase at the end of S-phase. Cells were fixed at different time points to sample the population for centromere localization of nascent CENP-A-SNAP in S, G2, mitosis (M) and G1-phase cells. While the nascent pool is labeled at 7 hours post release, it does not localize to the centromere until cells reach G1-phase. Cells are counterstained with anti-HA, which detects the total pool of (CENP-A-) SNAP. The merged image shows TMR-Star (green) and HA (red) signals together with DAPI stain (blue). (C) Combining quench-chase-pulse and pulse-chase labeling with RNAi. An asynchronous population of cells expressing CENP-A-SNAP were transfected with siRNAs to block synthesis of nascent CENP-A or of a control protein (GAPDH). Cells were then either pulse-chase labeled (left) or quench-chase-pulse labeled (right) at indicated time points and assayed 48 hours after siRNA addition to determine the fate of old and new pools of protein, respectively. CENP-A-SNAP::TMR-Star signals representing old and new protein pools are shown following RNAi. Cells were counterstained with CENP-C (green) and DAPI (blue) to visualize centromeres and DNA, respectively. TMR-Star centromere intensity levels at the centromere were determined by CRaQ (Basic 
Protocol 5). Average centromeric CENP-A-SNAP::TMR-Star signals were determined from 3 replicate experiments. Signals after GAPDH RNAi were set to 1. Error bars indicate standard error of the mean (SEM). While CENP-A RNAi impairs the synthesis and accumulation of nascent CENP-A (new pool) the pool synthesized prior to siRNA addition is unaffected, demonstrating the ability to differentially visualize old and new protein pools. Panel (B) is adapted from Jansen et al., 2007. $245 \times 260 \mathrm{~mm}(300 \times 300 \mathrm{DPI})$ 
Figure 5. Live cell imaging of SNAP labeled cells. Schematic outlines cell synchronization and quenchchase-pulse labeling steps as shown in Figure 4B. Following pulse labeling, cells are cycled into mitosis and mounted for live cell imaging (Basic Protocol 4). Time lapse series is shown of a cell in mitosis. At early time points, TMR-Star signals are non-centromeric, but are observed near the cell periphery, probably reflecting non-specific retention of the fluorescent substrate in cellular membranes. As cells exit from mitosis (after anaphase, $t=0$ minutes) TMR-Star signal accumulates at centromeres from $t=50$ minutes onwards. Cells express GFP-CENP-C that constitutively labels centromeres throughout the experiment. Insets show colocalization of nascent CENP-A-SNAP::TMR-Star (green) with centromeres (CENP-C, red). Image is adapted from Jansen et al., 2007. $202 \times 144 \mathrm{~mm}(300 \times 300 \mathrm{DPI})$ 


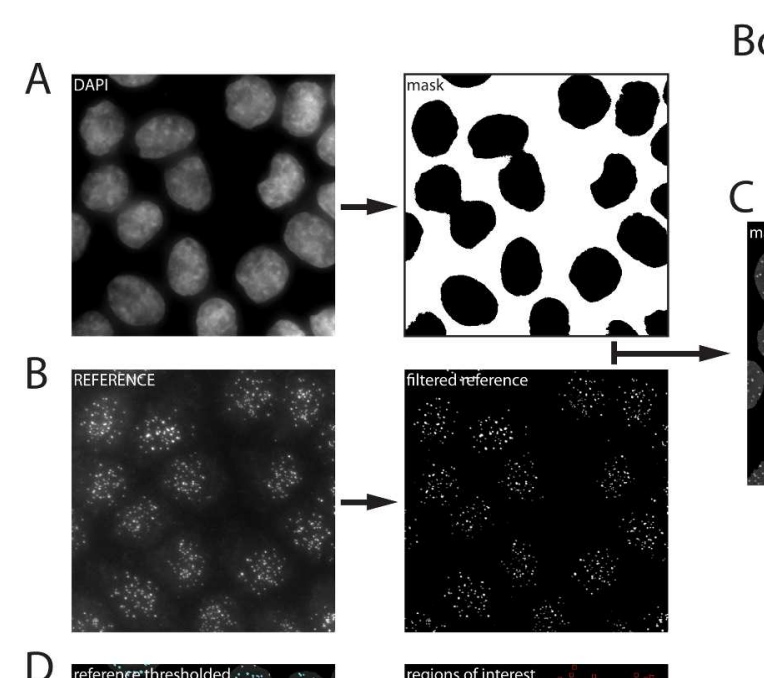

\section{Bodor et al., Figure 6}

D

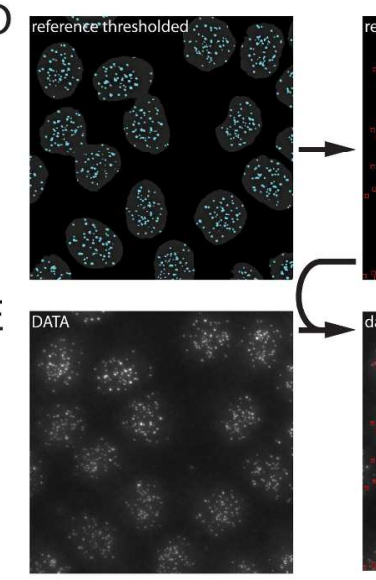

F
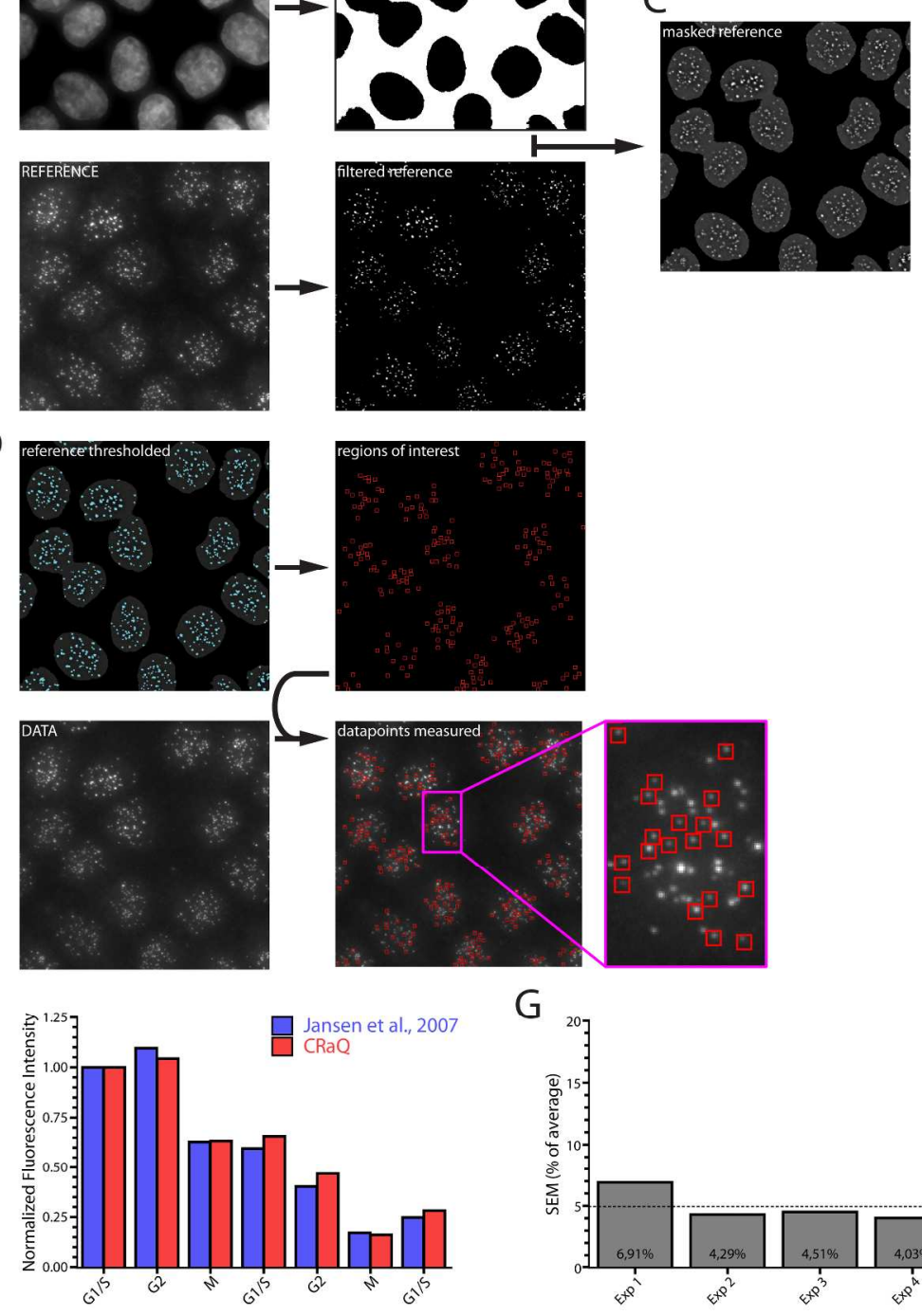

G

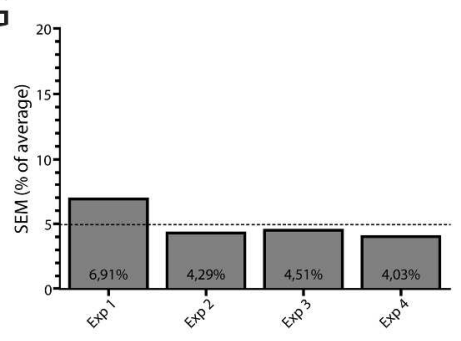

Figure 6. Centromere Recognition and Quantification (CRaQ). (A-E) Flow-scheme outlining automated steps of centromere recognition by CRaQ (Basic Protocol 5). (A) DAPI images are thresholded and converted to binary images (mask). (B) REFERENCE images are filtered and (C) overlaid with the mask to produce a masked reference image. (D) This image is again thresholded and spots that fit with the given parameter settings are exported as regions of interest (rois). (E) DATA images are measured at each roi.

The blowup shows accuracy and frequency of centromere recognition. Note that raw data images are indicated by capitals, while processed images are indicated by lowercase letters in A-E. (F) CRaQ was used to re-analyze measurements that were performed by manual selection and quantification in Jansen et al., 2007. The two methods result in practically identical quantifications, thus cross-validating both methods.

(G) Replicate samples were analyzed by CRaQ and standard error of mean (SEM) is plotted as a percentage of the average value for four independent experiments, each consisting of four replicate samples. $202 \times 289 \mathrm{~mm}(300 \times 300 \mathrm{DPI})$ 


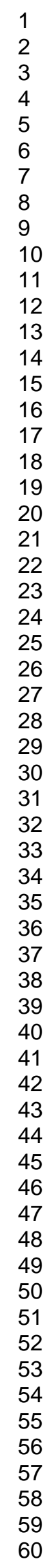

John Wiley \& Sons 
A

\section{Bodor et al., Figure 7}

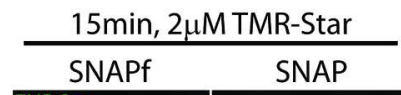

\begin{tabular}{cc}
$5 \mathrm{~min}, 2 \mu \mathrm{M}$ TMR-Star \\
\hline SNAPf & SNAP
\end{tabular}

\begin{tabular}{cc}
$5 \mathrm{~min}, 1 \mu \mathrm{M}$ TMR-Star \\
\hline SNAPf & SNAP
\end{tabular}
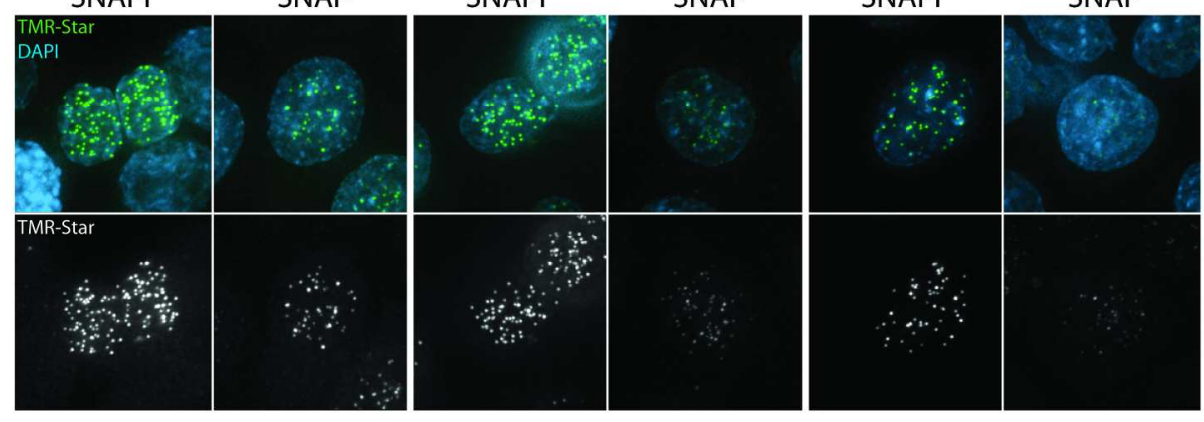

B

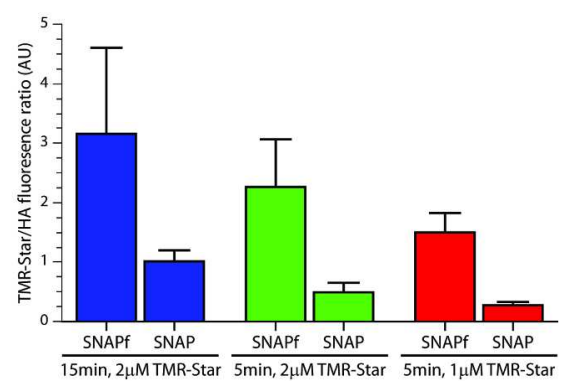

Figure 7. Evaluation of SNAPf-tag performance. (A) HeLa cells were transfected with either CENP-ASNAP or CENP-A-SNAPf fusion proteins, and labeled with TMR-Star at different concentrations and incubation times, as indicated in the figure. Representative images of cells are shown with TMR-Star signals in green and DAPI (DNA) in blue. (B) TMR-Star and HA fluorescence intensity were determined using CRaQ (Basic Protocol 5) and TMR-Star/HA ratios are used as a measure of SNAP or SNAPf activity. Results are plotted as fold difference, normalized to signals obtained with SNAP after incubation with $2 \mu \mathrm{M}$ TMR-Star for 15 minutes (standard conditions). SNAPf outperforms SNAP in all conditions tested (3-5 fold). $202 \times 161 \mathrm{~mm}(300 \times 300$ DPI $)$ 


\begin{tabular}{|c|c|c|c|c|c|c|c|c|}
\hline & & Description & Advantages & Disadvantages & Scale & Timescale & Examples & References \\
\hline \multirow{2}{*}{ 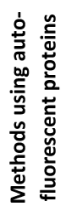 } & $\begin{array}{l}\text { Fluorescence Recovery } \\
\text { After Photobleaching } \\
\text { (FRAP) }\end{array}$ & $\begin{array}{l}\text { Measures local protein turnover } \\
\text { (time \& extent) after } \\
\text { photobleaching }\end{array}$ & $\begin{array}{l}\text { Allows analysis at very short } \\
\text { timescales (seconds-minutes) }\end{array}$ & $\begin{array}{l}\text { Not possible at long timescales } \\
\text { (hours-days); phototoxicity }\end{array}$ & single cells & seconds-minutes & FRAP, FLIP & $\begin{array}{l}\text { reviewed in: Lippincott-Schwartz } \\
\text { et al, } 2001\end{array}$ \\
\hline & $\begin{array}{c}\text { Fluorescence Correlation } \\
\text { Spectroscopy (FCS) }\end{array}$ & $\begin{array}{l}\text { Measures diffusion of fluorescent } \\
\text { proteins in a very small volume }\end{array}$ & $\begin{array}{l}\text { Allows accurate determination of } \\
\text { protein concetrations and diffusion } \\
\text { rates; single molecule sensitivity }\end{array}$ & $\begin{array}{c}\text { Only works for mobile proteins at } \\
\text { low concentrations; requires highly } \\
\text { specialized equipment }\end{array}$ & single cells & seconds & FCS, FCCS, RICS & $\begin{array}{l}\text { reviewed in: Lippincott-Schwartz } \\
\text { et al, } 2001\end{array}$ \\
\hline \multirow{2}{*}{ 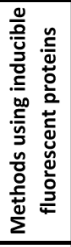 } & $\begin{array}{l}\text { Photo-activatable } \\
\text { fluorescent proteins } \\
\text { (PAFPs) }\end{array}$ & $\begin{array}{l}\text { Fluorescent proteins that can be } \\
\text { "turned on" by laser activation }\end{array}$ & $\begin{array}{l}\text { Allows analysis of a specific } \\
\text { subcellular pool of protein }\end{array}$ & $\begin{array}{l}\text { Fluorescence prior to activation; } \\
\text { phototoxicity }\end{array}$ & single cells & seconds-minutes & $\begin{array}{l}\text { Dronpa, Padron, } \\
\text { bsDronpa, PA-GFP, } \\
\text { PAmCherry }\end{array}$ & reviewed in: Lukyanov et al, 2005 \\
\hline & $\begin{array}{l}\text { Photo-convertible } \\
\text { fluorescent proteins } \\
\text { (PCFPs) }\end{array}$ & $\begin{array}{l}\text { Fluorescent proteins that can } \\
\text { "change color" upon laser } \\
\text { activation }\end{array}$ & $\begin{array}{c}\text { Allows analysis of subcellular protein } \\
\text { pools ; visaulization prior to } \\
\text { activation; low background in post- } \\
\text { activation channel }\end{array}$ & $\begin{array}{l}\text { Blocks two fluorescent channels; } \\
\text { phototoxicity }\end{array}$ & single cells & seconds-minutes & $\begin{array}{c}\text { mEos2, Kaede, } \\
\text { Dendra-2, KiKGR, PS- } \\
\text { CFP2 }\end{array}$ & reviewed in: Lukyanov et al, 2005 \\
\hline \multirow{3}{*}{ 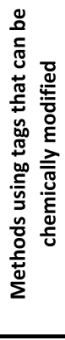 } & Chelation based tags & $\begin{array}{l}\text { Short peptide tags that have } \\
\text { affinity to chemical substances }\end{array}$ & Size (6-12aa's) & Unspecific labeling; toxicity & single cells/bulk & hours & $\begin{array}{c}\text { TC-tag, 6His-tag, Poly. } \\
\text { D-tag }\end{array}$ & reviewed in O'Hare et al, 2007 \\
\hline & $\begin{array}{l}\text { Post translational } \\
\text { modification (PTM) } \\
\text { based tags }\end{array}$ & $\begin{array}{l}\text { Tags that can be specifically post- } \\
\text { translationally modified by } \\
\text { (artificial) groups }\end{array}$ & Size (4-80aa's) & $\begin{array}{l}\text { Requires foreign enzyme or } \\
\text { coexpression of enzyme to catalyze } \\
\text { reaction }\end{array}$ & single cells/bulk & & $\begin{array}{l}\text { ACP/PCP, Biotin, } \\
\text { sulfatase, } Q \text {-tag }\end{array}$ & reviewed in O'Hare et al, 2007 \\
\hline & Self labeling tags & $\begin{array}{l}\text { Enzymes that catalyze their } \\
\text { covalent binding to small } \\
\text { compounds }\end{array}$ & $\begin{array}{c}\text { Allows measurements at long } \\
\text { timescales; allows analysis of 'old' vs } \\
\text { 'new' protein pools }\end{array}$ & $\begin{array}{l}\text { Does not allow measurements at } \\
\text { short timescales (sec-min); high } \\
\text { fluorescent background in live cells }\end{array}$ & single cells/bulk & hours-days & $\begin{array}{l}\text { SNAP, SNAPf, CLIP, } \\
\text { CLIPf, Halo, TMP }\end{array}$ & $\begin{array}{c}\text { Keppler et al, } 2003 \text { (SNAP); Los and Wood, } \\
\text { 2007 (Halo); Gautier et al, 2008 (CLIP); } \\
\text { Gallagher et al, } 2009 \text { (TMP); Sun et al, } \\
2011 \text { (SNAPf); reviewed in O'Hare et al, } \\
20007 \\
\end{array}$ \\
\hline \multirow{3}{*}{ 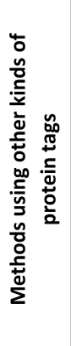 } & $\begin{array}{c}\text { Time Specific Tag for Age } \\
\text { Measurement of Proteins } \\
\text { (TimeSTAMP) }\end{array}$ & $\begin{array}{l}\text { Self degrading protein tag that is } \\
\text { inhibited by drug addition }\end{array}$ & $\begin{array}{l}\text { Drug is sufficiently small to allow } \\
\text { accessibility into tissues of live } \\
\text { animals }\end{array}$ & $\begin{array}{l}\text { Only allows analysis of new protein } \\
\text { pools }\end{array}$ & bulk; tissues & hours & see Lin et al, 2008 & Lin et al, 2008 \\
\hline & $\begin{array}{l}\text { Recombination Induced } \\
\text { Tag Exchange (RITE) }\end{array}$ & $\begin{array}{c}\text { Floxed protein tag that is replaced } \\
\text { by a different tag upon Cre- } \\
\text { expression }\end{array}$ & $\begin{array}{l}\text { Allows measurements of both old } \\
\text { and new protein pools } \\
\text { simultaneously }\end{array}$ & $\begin{array}{c}\text { Analysis depends on efficiency of Cre } \\
\text { recombination }\end{array}$ & single cells/bulk & hours (days?) & $\begin{array}{l}\text { see Verzijlbergen et } \\
\text { al, 2010;Radman- } \\
\text { Livaja et al, } 2011\end{array}$ & Verzijlbergen et al, 2010 \\
\hline & $\begin{array}{l}\text { Auxin-inducible degron } \\
\text { system (AID system) }\end{array}$ & $\begin{array}{c}\text { Inducible degradation tag, through } \\
\text { cell-exogenous proteasome }\end{array}$ & $\begin{array}{c}\text { Allows rapid specific degradation of } \\
\text { a tagged pool of protein }\end{array}$ & $\begin{array}{l}\text { Requires introduction of multiple } \\
\text { transgenes; only allows analysis of } \\
\text { new protein pools }\end{array}$ & single cells/bulk & minutes-hours & $\begin{array}{c}\text { see Nishimura et al, } \\
2009\end{array}$ & Nishimura et al, 2009 \\
\hline \multirow{2}{*}{ 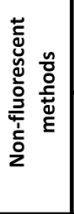 } & $\begin{array}{c}\text { Western-blot based } \\
\text { pulse-chase experiments }\end{array}$ & $\begin{array}{l}\text { Conditionally controlled expression } \\
\text { and inhibition of protein synthesis }\end{array}$ & $\begin{array}{c}\text { cheap, easy, no need for specilized } \\
\text { equipment }\end{array}$ & $\begin{array}{l}\text { Does not allow imaging; cell toxity } \\
\text { due to protein synthesis inhibitors }\end{array}$ & bulk & hours & many & \\
\hline & $\begin{array}{l}\text { Metabolic labeling of } \\
\text { proteins }\end{array}$ & $\begin{array}{l}\text { Pulse labeling using labeled amino } \\
\text { acids or amino acid analogs }\end{array}$ & $\begin{array}{l}\text { No requirement for transgenes or } \\
\text { tags }\end{array}$ & $\begin{array}{c}\text { All proteins are labeled } \\
\text { simultaneously, thus requiring } \\
\text { downstream techniques to purify } \\
\text { proteins of interest }\end{array}$ & bulk & minutes-days & SILAC, CATCH-IT & Ong et al, 2002; Deal et al, 2010 \\
\hline
\end{tabular}

John Wiley \& Sons 


\begin{tabular}{|c|c|c|c|}
\hline SNAP-substrate labels & Specifications & Examples & References \\
\hline Quenchers & $\begin{array}{l}\text { Used to block (quench) pre-existing pools of SNAP protein to prevent } \\
\text { their detection in subsequent labeling steps. }\end{array}$ & BG, BTP & $\mathrm{NEB}^{8}$ \\
\hline \multicolumn{4}{|l|}{ Fluorescent substrates } \\
\hline Standard fluorophores ${ }^{1}$ & Used for most microscopy based pulse-labeling techniques. & $\begin{array}{l}\text { TMR-Star; BG-AF; BG } \\
\text { Cy3 }\end{array}$ & NEB ${ }^{8}$, Keppler et al, 2004 \\
\hline Dark-dyes (induced quenching) ${ }^{2}$ & $\begin{array}{l}\text { reduced fluorescence prior to binding to SNAP. Allows for wash-free } \\
\text { labeling and better signal to noise. }\end{array}$ & $\begin{array}{l}\text { CBG-549-QSY7, } \\
\text { DRBGFL }\end{array}$ & $\begin{array}{l}\text { Sun et al, 2011; Komatsu et al, } \\
2011\end{array}$ \\
\hline Dark-dyes (natural quenching) ${ }^{3}$ & $\begin{array}{l}\text { reduced fluorescence prior to binding to SNAP. Allows for wash-free } \\
\text { labeling and better signal to noise. }\end{array}$ & BG-MR121 & Stöhr et al, 2010 \\
\hline Caged dyes ${ }^{4}$ & $\begin{array}{l}\text { Substrate that becomes fluorescent after UV-activation (analogous to } \\
\text { photo-activatable fluorescent proteins). }\end{array}$ & $\begin{array}{l}\text { N9NPE-BG-FL; } \\
\text { BG-CMNB-caged }\end{array}$ & $\begin{array}{l}\text { Banala et al, 2010; Campos et al, } \\
2011\end{array}$ \\
\hline Photo-activatable dyes ${ }^{5}$ & Used for PALM/STORM of SNAP labeled proteins. & BG-Су3-Сy5 & $\begin{array}{l}\text { Maurel et al, 2010; Dellagiacoma } \\
\text { et al, } 2011\end{array}$ \\
\hline \multicolumn{4}{|l|}{ Protein purification substrates } \\
\hline Beads $^{6}$ & Used for SNAP protein extraction from cell lysates. & $\begin{array}{l}\text { BG-beads (agarose } \\
\text { or magnetic) }\end{array}$ & $\mathrm{NEB}^{8}$ \\
\hline Biotinylation & $\begin{array}{l}\text { Used for SNAP protein extraction from cell lysates, using streptavidin } \\
\text { beads. }\end{array}$ & BG-Biotin & $\mathrm{NEB}^{8}$ \\
\hline \multicolumn{4}{|l|}{ Other types of substrates ${ }^{7}$} \\
\hline Photosensitizer & $\begin{array}{l}\text { Used to selectively sensitize cancer cells to non-hazardous light after } \\
\text { fusing SNAP to an antibody that recognizes tumor cells. }\end{array}$ & BG-Ce6 & Hussain et al, 2011 \\
\hline Anti-obesity drugs & $\begin{array}{l}\text { Used to deliver a drug to the correct subcellular compartments for } \\
\text { optimal activity in vivo. }\end{array}$ & BG-THL & Yang et al, 2011 \\
\hline Thiol & $\begin{array}{l}\text { Used for generation of self-assembled-monolayers (SAM) by } \\
\text { microcontact printing }\end{array}$ & BG-Thiol & Engin et al, 2010 \\
\hline \multicolumn{4}{|l|}{ Many more .... } \\
\hline \multicolumn{4}{|c|}{ A broad spectrum of colors have been reported that range from ultraviolet to infrared fluorescent dyes (e.g. available from NEB and in Keppler et al, 2004, 2006, Bojkowska 2011). } \\
\hline \multirow{2}{*}{\multicolumn{4}{|c|}{$\begin{array}{l}\text { Fluorescent BG substrates are labeled to a second sidegroup that quenches the fluorescence by FRET. After protein labeling, the two sidegroups are spatially removed leading to increased fluorescence. } \\
\text { As above, except that fluoroohores are used that are naturally quenched by guanine, alleviating the need for adding a second (bulky) sidechain. }\end{array}$}} \\
\hline & & & \\
\hline \multicolumn{4}{|c|}{${ }^{4}$ Caged dyes have a photoremovable group that quenches fluorescence and is chemically removed upon irradiation with UV light. } \\
\hline \multicolumn{4}{|c|}{${ }^{5}$ One reason to use these dyes for superresolution microscopy, is their increased brightness as compared to fluorescent proteins; a limiting factor for these techniques. } \\
\hline \multicolumn{4}{|c|}{${ }^{6}$ SNAP enzyme activity must be preserved in the lysate, as binding occurs through reaction with SNAP } \\
\hline \multicolumn{4}{|c|}{$\begin{array}{l}7 \text { BG derivatives can be readily synthesized by standard biochemical methods for essentially any kind of sidegroup, ranging from relatively small molecules (e.g. fluorophores, Keppler et al, 2004) to very large } \\
\text { thiol molecules (e.g. matrix thiol, Engin et al, 2010). A small number of interesting examples is given. }\end{array}$} \\
\hline \multicolumn{4}{|c|}{${ }^{8} \mathrm{New}$ England Biolabs } \\
\hline
\end{tabular}

